\title{
The business case for social and behavior change for malaria with applications for Côte d'Ivoire and Tanzania
}

Breakthrough RESEARCH

Follow this and additional works at: https://knowledgecommons.popcouncil.org/departments_sbsr-pgy How does access to this work benefit you? Let us know!

\section{Recommended Citation}

"The business case for social and behavior change for malaria with applications for Côte d'Ivoire and Tanzania," Breakthrough RESEARCH Technical Report. Washington, DC: Population Council. 


\section{TECHNICAL REPORT}

\section{The Business Case for Social and Behavior Change for Malaria with Applications for Côte d'Ivoire and Tanzania}

JUNE 2021

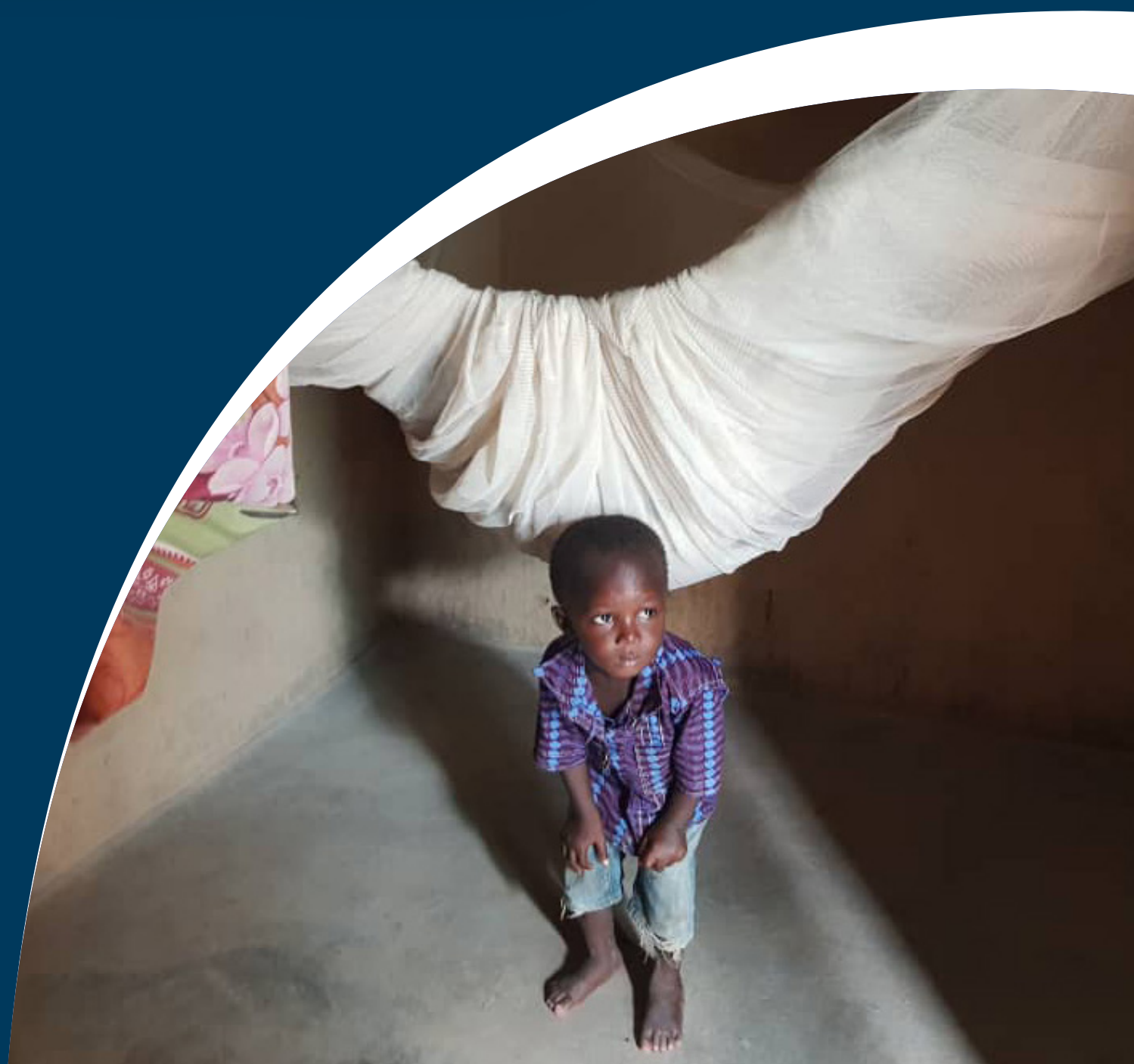




\section{Acknowledgments}

We are grateful to the many people who helped develop this document. We thank the many Breakthrough RESEARCH and Breakthrough ACTION colleagues who provided insights and our Breakthrough RESEARCH USAID management team who provided suggestions and guidance throughout.

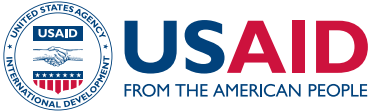

Breakthrough RESEARCH is made possible by the generous support of the American people through the United States Agency for International Development (USAID) under the terms of cooperative agreement no. AID-OAA-A-17-00018. The contents of this document are the sole responsibility of Breakthrough RESEARCH and Population Council and do not necessarily reflect the views of USAID or the United States Government.

\section{Breakthrough
RESEARCH
FOR SOCIAL \& BEHAVIOR CHANGE}

Breakthrough RESEARCH catalyzes social and behavior change (SBC) by conducting state-of-the-art research and evaluation and promoting evidence-based solutions to improve health and development programs around the world. Breakthrough RESEARCH is a consortium led by the Population Council in partnership with Avenir Health, ideas42, Institute for Reproductive Health at Georgetown University, Population Reference Bureau, and Tulane University.

\section{POPULATION \\ COUNCIL}

Ideas. Evidence. Impact.

The Population Council confronts critical health and development issuesfrom stopping the spread of HIV to improving reproductive health and ensuring that young people lead full and productive lives. Through biomedical, social science and public health research in about 50 countries, the Council works with our partners to deliver solutions that lead to more effective policies, programs, and technologies to improve lives worldwide. Established in 1952 and headquartered in New York, the Council is a nongovernmental, nonprofit organization with an international board of trustees.

\section{Avenir Health}

Avenir Health was founded in 2006 as a global health organization that works to enhance social and economic development by providing tools and technical assistance in policy, planning, resource allocation and evaluation. Its focus is on developing and implementing demographic, epidemiological and costing models for long-range planning to assist with setting goals, strategies, and objectives. Avenir Health assists in both developing and implementing programs in HIV/AIDS, reproductive health, maternal health and other programming areas. Avenir Health works with government agencies, foundations, corporations, and nongovernmental organizations around the world.
(C)2021 The Population Council. All rights reserved.

Cover photo by US Government works

\section{Suggested Citation}

Avenir Health. 2021. "The business case for social and behavior change for malaria with applications for Côte d'Ivoire and Tanzania," Breakthrough RESEARCH Technical Report. Washington, DC: Population Council.

\section{Contact}

4301 Connecticut Avenue NW, Suite 280 | Washington, DC 20008 +1 2022379400 | BreakthroughResearch@popcouncil.org breakthroughactionandresearch.org 
The Business Case for Social and Behavior Change for Malaria with Applications for Côte d'Ivoire and Tanzania

\section{Avenir Health}




\section{Acronyms}

ACT Artemisinin-based combination therapy

DALY Disability-adjusted life year

GBD Global Burden of Disease project

GDP Gross domestic product

ICER Incremental cost-effectiveness ratio

IPC Interpersonal communication

IPTp Intermittent preventive treatment in pregnancy

IRS Indoor residual spraying

ITN Insecticide-treated net

LMIC Low- or middle-income country

OR Odds ratio

PMI US President's Malaria Initiative

Programme Nationale de Lutte contre le Paludisme

PNLP (national malaria control program, Côte d'Ivoire)

SBC Social and behavior change

SBCC Social and behavior change communication

SMS Short message service

TMIS Tanzania Malaria Indicator Survey

USAID $\quad$ US Agency for International Development

USD US dollars

WHO World Health Organization 


\section{Table of Contents}

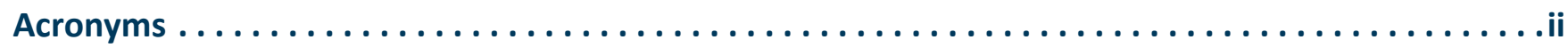

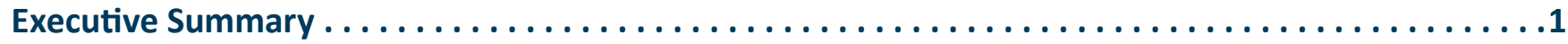

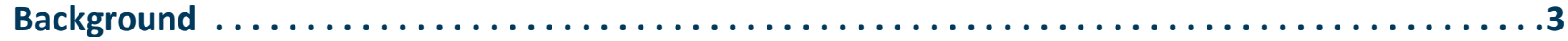

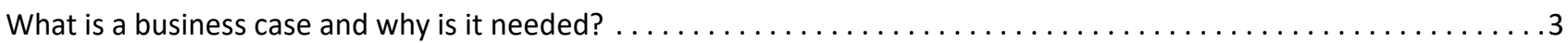

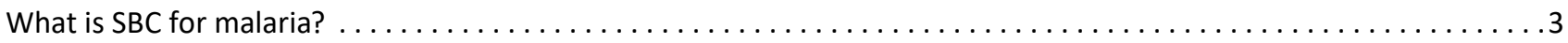

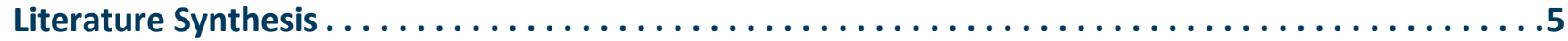

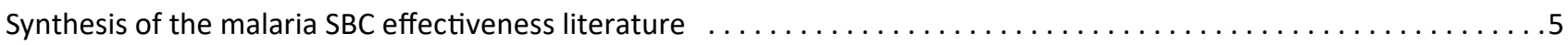

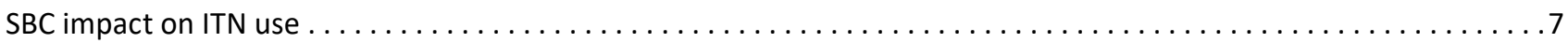

SBC impact on care seeking for fever and treatment adherence as components of case management

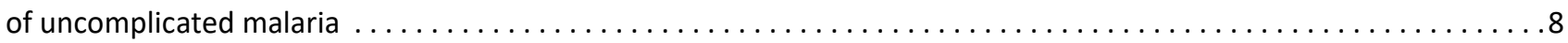

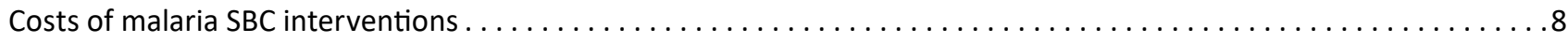

Assessing Cost-effectiveness......................................... 10

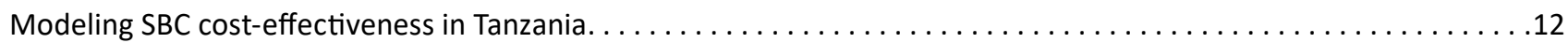

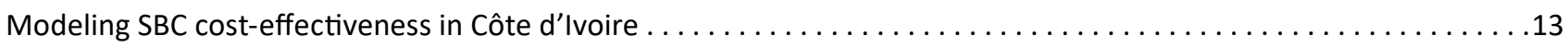

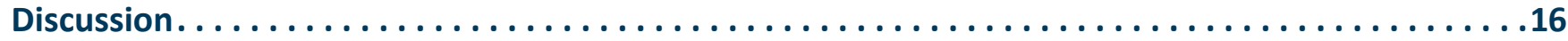

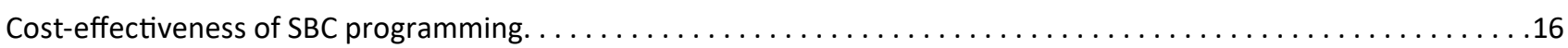

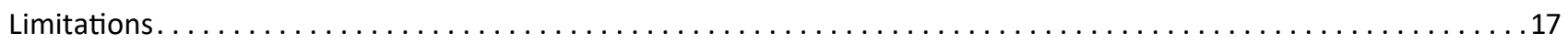

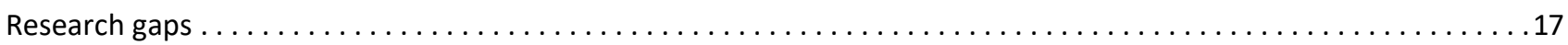

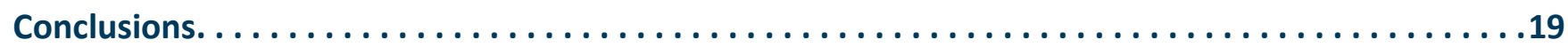

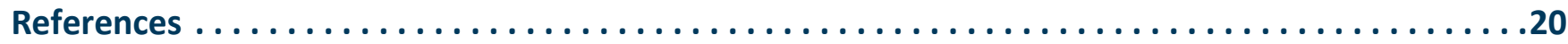

Appendix A: Additional methodological details . . . . . . . . . . . . . . . . . 22

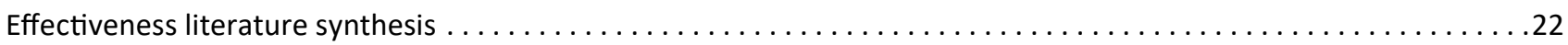

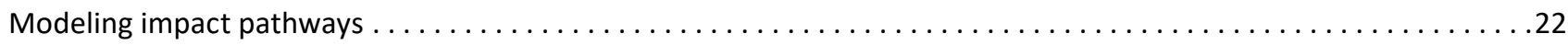

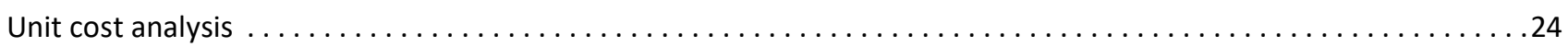

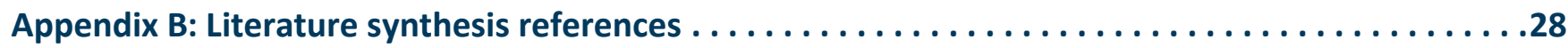




\section{Executive Summary}

Social and behavior change (SBC) interventions like mass media, interpersonal communication (IPC), and community engagement play a critical role in improving health outcomes by facilitating positive change in health-seeking behaviors, community norms, and environmental factors. While SBC investments are considered critical to improving health-seeking behaviors, gaps in information on the costs and impacts of SBC interventions have resulted in an incomplete picture of the value of SBC interventions, their contributions to social and health outcomes, and potential cost savings from implementing SBC programming. To address these gaps, the US President's Malaria Initiative (PMI) tasked Breakthrough RESEARCH with creating a business case for SBC in malaria. This document summarizes the findings from this activity, including a synthesis of SBC effectiveness and cost literature and cost-effectiveness modeling applications for Tanzania and Côte d'Ivoire.

\section{Methods}

Assessing the cost-effectiveness for malaria SBC requires four main ingredients: (1) a synthesis of the malaria SBC effectiveness literature, (2) a synthesis of the SBC cost literature for health interventions, (3) a collation of baseline data on malaria prevention and treatment behaviors and related behavioral determinants from application countries, and (4) investment scenarios that can model improvement in health behaviors and subsequent impact on malaria cases and deaths due to SBC activities. Building on prior work by Breakthrough RESEARCH and Breakthrough ACTION and utilizing the Spectrum Malaria software, a model was constructed that estimates the impact of malaria SBC on malaria cases and deaths; the expected costs of malaria SBC and related costs (e.g., additional service delivery costs); and the resulting cost per disability-adjusted life year (DALY) averted, meaning the cost to add one year of healthy life.

Using the Health Communication Capacity Collaborative database of SBC effectiveness studies and targeted searches, 112 effectiveness studies were extracted into an Excel-based study results database. Among observations with the same SBC intervention and intermediate determinant or behavioral outcome category, median odds ratios were calculated for pathways linking malaria SBC to two priority outcomes: (1) use of insecticide-treated nets (ITNs) and (2) care seeking for

The outcome variables are focused on ITN usage but vary in their exact specification and included both correct and consistent use of ITNs, always use ITNs, and slept under an ITN the previous night. fever ${ }^{b}$ and treatment adherence as components of case management of uncomplicated malaria cases (defined as the completion of a full course of recommended antimalarial treatment). There was insufficient literature to model the impact of SBC on intermittent preventive treatment in pregnancy (IPTp).

For SBC costs, data from 147 SBC cost studies from all health areas were extracted into an SBC cost repository, and 120 observations were used to estimate median unit costs per SBC intervention. Unit costs for mass media interventions like radio and television were measured as per person exposed. For two-way communication like IPC and intervention packages of multicomponent SBC interventions, the costs were summarized as per person participating. For mobile phone and text message reminders, the unit cost was per person contacted.

Baseline data on malaria indicators and initial five-year investment scenarios for malaria SBC in Tanzania and Côte d'Ivoire were obtained through a document review of PMI malaria operational plans for fiscal years 2019 and 2020 and country reports of USAID-funded malaria SBC intervention implementation via the Tulonge Afya and the Global Fund-funded Kiungo cha Mabadiliko ya Kutokomeza Ugonjwa wa Malaria projects in Tanzania and Breakthrough ACTION in Côte d'Ivoire.

Using these inputs, a cost-effectiveness model was created where the impact of SBC interventions on ITN

${ }^{\text {DT}}$ The outcome variables are focused on fever care seeking but vary in their exact specification and included both prompt care seeking within 24 hours, within 48 hours, and without a time reference. 
use and fever care seeking and treatment adherence outcomes was estimated. Changes in outcomes were input into the Spectrum Malaria model to estimate the number of deaths and malaria cases averted, which were then translated into DALYs averted. The total costs associated with malaria SBC and additional direct costs from increases in ITNs, malaria diagnosis, and treatment were divided by the total DALYs averted to generate a cost per DALY averted that can be compared to a country's per capita gross domestic product (GDP) to assess cost-effectiveness, where a cost per DALY averted below the national GDP per capita is considered highly cost-effective.

\section{Results}

The effectiveness evidence shows that SBC interventions are effective in improving ITN use and fever care seeking and treatment adherence, both directly and, where enough prior literature was available for modeling, indirectly through intermediate determinant variables, which included knowledge, attitudes, and self-efficacy, and communication about malaria between friends, family, and neighbors. In terms of unit costs, the median costs per person exposed to mass media interventions are low, less than $\$ 0.50$ per person exposed. In contrast, median IPC costs are $\$ 4.59^{\circ}$ per person participating in group IPC. Median short message service (SMS) reminders are $\$ 2.08$ per person contacted. The costs per person participating and contacted are higher than costs per person exposed due to their more intensive programming and more limited population reach.

In Tanzania, the national malaria incidence is 124 per 1,000 population at risk. A five-year SBC investment of $\$ 43.2$ million resulted in approximately 6.8 million malaria cases averted and 7,763 deaths averted, onethird among children under 5 years old. Factoring in the total costs and total DALYs associated with averted malaria cases and deaths, the cost per DALY averted was $\$ 124$. This result is highly cost-effective as a health intervention using the GDP per capita threshold as recommended by the World Health Organization, even when allowing higher unit costs when performing a sensitivity analysis.

In Côte d'Ivoire, the malaria incidence is 331 per 1,000 population at risk. The malaria burden is borne primarily
RESULTS AT A GLANCE

\begin{tabular}{|c|c|c|}
\hline & TANZANIA & CÔTE D'IVOIRE \\
\hline $\begin{array}{l}\text { Percentage point increase in ITN } \\
\text { use }\end{array}$ & 4.8 & 1.5 \\
\hline $\begin{array}{l}\text { Percentage point increase in } \\
\text { appropriate case management } \\
\text { for uncomplicated malaria }\end{array}$ & 3.7 & 3.5 \\
\hline Malaria cases averted & 6.8 million & 1.2 million \\
\hline Malaria deaths averted & 7,763 & 5,291 \\
\hline $\begin{array}{l}\text { Cost per disability-adjusted } \\
\text { life year averted }\end{array}$ & $\$ 124$ & $\$ 63$ \\
\hline $\begin{array}{l}\text { Cost-effectiveness } \\
\text { determination }\end{array}$ & $\begin{array}{l}\text { Highly } \\
\text { cost-effective }\end{array}$ & $\begin{array}{l}\text { Highly } \\
\text { cost-effective }\end{array}$ \\
\hline
\end{tabular}

among young children under 5 years old, and it is the largest cause of death in this age group. An initial SBC investment scenario of approximately $\$ 16.8$ million over five years resulted in over 1.2 million averted malaria cases and 5,291 averted deaths, mostly among children under 5 years old. The resulting cost per DALY averted for the malaria SBC program was $\$ 63$, also highly cost-effective and far below the threshold $(\$ 2,032)$ for a highly cost-effective intervention in Côte d'Ivoire.

\section{Implications and limitations}

The creation of the SBC business case for malaria resulted in several interesting findings. First, the results provide evidence that SBC interventions are effective in improving malaria behaviors and that investments in $\mathrm{SBC}$ can be a highly cost-effective means of reducing the mortality and morbidity associated with malaria. When comparing these estimates to a variety of malaria interventions reported in the literature, which may or may not include SBC components, the findings shown in this analysis appear to be comparable; however, the costs per DALY averted with malaria programming reported in the literature vary widely based on the intervention, study methodology, and expression of results. The difference in results in Tanzania and Côte d'Ivoire has multiple causes, but the largest drivers are the overall larger burden of malaria in Côte d'Ivoire and the disproportionate impact these interventions have on saving the lives of children under 5 years old, as opposed to Tanzania where malaria burden is more evenly spread throughout the age distribution.

${ }^{\text {c} A l l ~ c o s t s ~ r e p r e s e n t e d ~ i n ~ t h e ~ m a l a r i a ~ b u s i n e s s ~ c a s e ~ a r e ~ i n ~} 2019$ US dollars. 


\section{Background}

Social and behavior change (SBC) interventions play a critical role in improving health outcomes by facilitating positive change in health-seeking behaviors and the community norms and environmental factors underlying them. ${ }^{1}$ These are achieved through a myriad of interventions, including mass and digital media (e.g., radio, text messages); interpersonal communication (IPC); provider training; and community mobilization. SBC experts draw on many disciplines, including social psychology, marketing, and behavioral economics, to design interventions that are grounded in behavioral theory, applied research, and program evaluation findings. ${ }^{2}$

In 2019, the Breakthrough RESEARCH Business Case for Investing in Social and Behavior Change for Family Planning synthesized the literature on SBC effectiveness and costs and modeled the cost-effectiveness of SBC investments in family planning. ${ }^{3}$ The business case for family planning revealed that SBC interventions can be cost-effective and detailed the pathways through which SBC interventions increased modern contraceptive use. The US President's Malaria Initiative (PMI) then asked Breakthrough RESEARCH in late 2019 to develop a business case for SBC in malaria. This document summarizes both the findings from the literature synthesis for the business case and models the impact of SBC malaria programming investments for Tanzania and Côte d'Ivoire.

\section{What is a business case and why is it needed?}

A business case in the global health field presents a rationale for investing in a particular health area or intervention by analyzing the costs and benefits. Although SBC investments are considered critical to improving health-seeking behaviors, gaps in information on the value of SBC interventions, their contributions to social and health outcomes, and potential cost savings from investing in SBC persist. This business case for SBC in malaria uses an evidence-based approach to address this imbalance by answering questions about the effectiveness, cost, and cost-effectiveness of malaria SBC on improving and maintaining key malaria prevention and treatment behaviors. The results of this analysis are aimed at various audiences, including international donors funding or potentially funding SBC activities, health and finance ministries to highlight the benefits of investing in malaria SBC activities, SBC implementers, and researchers. $^{3}$

\section{What is SBC for malaria?}

Despite declines in malaria cases and mortality in recent years, malaria continues to cause high levels of morbidity and mortality. In 2019, there were an estimated 229 million malaria cases and 409,000 malaria-related deaths worldwide, with a disproportionate burden in sub-Saharan Africa and the highest risk of death among children under 5 years old. ${ }^{4}$ Interventions at national and/ or local levels are implemented to reduce the morbidity and mortality associated with malaria, but not everyone is reached by the interventions. According to the US Centers for Disease Control and Prevention, the essential package of malaria interventions in most malaria-endemic countries includes:

- Case management, including prompt care seeking for fever and treatment adherence

- Use of insecticide-treated nets (ITNs)

- Intermittent preventive treatment of malaria in pregnancy (IPTp)

- Indoor residual spraying (IRS) of households ${ }^{5}$

SBC interventions can contribute to the adoption and maintenance of these interventions by influencing the cognitive, emotional, and social factors associated with them, which are posited by many theories as intermediate determinants of behavioral action. For example, improving attitudes on the effectiveness of malaria tests can increase care seeking and demand for testing among patients and caregivers with malaria symptoms. The term "SBC" encompasses many different types of interventions, which can be classified into the broader categories listed in Table 1. "Mass media" and "mid-media" generally refer to SBC messages directed to people through radio, television, and billboards/flyers. Community media are more local and involve live dramas, loudspeaker announcements, and community radio. In contrast, IPC is more focused on two-way communication with people through individual or group counseling. Provider behavior 
TABLE 1 SBC INTERVENTION CATEGORIES AND INTERVENTIONS

\begin{tabular}{|ll|}
\hline SBC CATEGORY & SBC INTERVENTIONS \\
\hline Mass media and mid-media & Radio campaigns \\
& TV campaigns \\
& Billboards/posters/flyers \\
\hline Community media & Live dramas (i.e., stage plays, street shows) \\
& Awareness raising activities (e.g., loudspeaker announcements) \\
& Community radio \\
\hline Interpersonal communication & Individual/household counseling, including counseling delivered during ITN distribution campaigns \\
Provider behavior change & $\begin{array}{l}\text { Provider interventions to address determinants of provider behavior (e.g., provider attitudes and } \\
\text { communication skills) }\end{array}$ \\
\hline Digital and social media & $\begin{array}{l}\text { Mobile phone and text messaging, including appointment and medication reminders and social } \\
\text { media }\end{array}$ \\
\hline SBC packages & IPC and mass media \\
\end{tabular}

change works at the provider level to address determinants of provider behavior, such as influencing attitudes and improving communication between providers and their clients. Digital and social media interventions can provide targeted information about appointment and medication reminders through text messages and address other behavioral determinants via social media platforms. Finally, many SBC interventions do not focus on any one type but rather combine various strategies into bundled interventions or "packages" for a comprehensive approach to SBC, which can include working with community leaders and reference groups to shape norms (e.g., gender norms) at the community level that influence individual health behaviors in addition to the interventions described above.
It is important to note that $\mathrm{SBC}$ is recognized as a critical component of programming for improving health-seeking behaviors and outcomes and is integrated into most malaria interventions. For example, ITN distribution campaigns are typically accompanied by both community announcements and IPC at the point of delivery. However, because SBC-specific costs are rarely examined in relation to the effectiveness of malaria behavioral or epidemiological outcomes, the cost-effectiveness of SBC in malaria is largely unknown. 


\section{Literature Synthesis}

To assess the cost-effectiveness for malaria SBC, we looked to the SBC literature to inform a model that examines the costs and benefits expected from SBC investments in malaria. Building this model requires four main ingredients: (1) a synthesis of the malaria SBC effectiveness literature, (2) a synthesis of the SBC cost literature for health interventions, (3) baseline data on malaria prevention and treatment behaviors and related behavioral determinants from application countries, and (4) investment scenarios that can be used to model improvement in health behaviors and subsequent impact on malaria cases and deaths due to SBC activities. To assemble these ingredients, we built on prior work in the literature. For effectiveness, we utilized the malaria database of effectiveness studies developed under the Health Communication Capacity Collaborative project and maintained by Breakthrough ACTION. ${ }^{6}$ Additionally, we leveraged prior work on SBC costs, where we conducted a review of the $\mathrm{SBC}$ cost literature to estimate median unit costs for SBC activities.?

\section{Synthesis of the malaria SBC effectiveness literature}

The primary objective of the effectiveness literature extraction was to generate evidence-based summary odds ratios (ORs) that link SBC interventions to three malaria behavioral outcomes: ITN use, care seeking for fever and treatment adherence as components of malaria case management, and IPTp use. This required summarizing evidence in three main categories (Figure 1):

1. Linking SBC interventions to intermediate determinants of behavior (e.g., IPC improving attitudes toward ITNs).

2. Linking intermediate determinants to behavioral outcomes, (e.g., improved attitudes toward ITNs).

3. Directly linking SBC interventions to behavioral outcomes (e.g., IPC improving ITN use).

When linking SBC interventions to outcomes, we relied on a previous comprehensive literature search of studies from 1996 to 2016 culminating in the Breakthrough ACTION database. A supplementary literature search was conducted by Breakthrough RESEARCH to capture studies from January 2016 to March 2020. All newly added studies were subject to abstract and (if eligible) full-text review. Additionally, studies from the SBC cost extraction with relevant effectiveness data were also included, as were studies from a previously conducted family planning SBC business case with malaria outcomes.

In total, 119 malaria studies were initially screened, with 77 meeting the inclusion criteria and extracted. The inclusion criteria were that the study: (1) described an SBC intervention; (2) was located in a designated low- or middle-income country at the time of intervention; (3) had a comparison group (at minimum a study design

\section{FIGURE 1 LITERATURE SYNTHESIS STRATEGY}

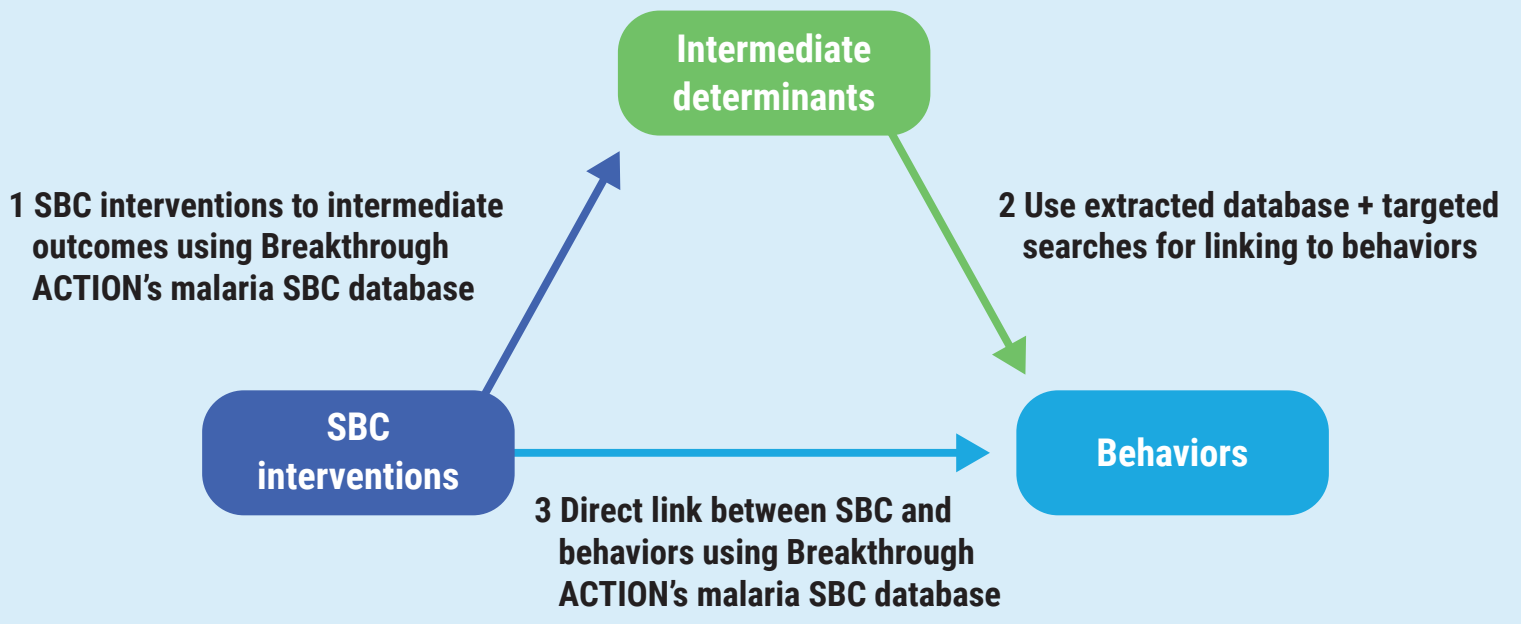


with intervention/control, pre/post, or exposed/unexposed groups); and (4) included an outcome related to malaria. In addition to the malaria behavioral outcomes, data were also extracted related to SBC's impact on various intermediate determinants of malaria behaviors, including:

- Improved knowledge about malaria causes, symptoms, prevention, and treatment.

- Improved attitudes around malaria and prevention, including self-efficacy to use ITNs and adhere to malaria medications.

- Improved communication about malaria and prevention with family, friends, or others.

The SBC intervention classification of each line item in the impact extraction database was reviewed and classified by the major intervention types detailed in

Table 1 (mass and mid-media, community media, IPC, provider behavior change, digital and social media, and SBC packages). SBC packages can include a range of configurations and often include a combination of mass media, interpersonal counseling, provider training, and/ or community mobilization.

In addition to behavioral outcomes, intermediate determinants were aligned with documentation from the RBM Partnership to End Malaria. ${ }^{8}$ The intermediate outcomes were first analyzed to see which determinants had sufficient evidence from the literature to use for modeling. "Sufficient evidence" was defined as having at least three different studies looking at the same relationship or two studies with one being a randomized controlled trial (e.g., three or more studies examining mass media and positive attitudes about malaria prevention). During this process, the intermediate outcomes were first divided into three groups: (1) malaria knowledge, (2) attitudes about malaria prevention and treatment and self-efficacy for ITN use and malaria treatment adherence, and (3) communication about malaria or ITNs with friends, family, and/or others.

With several studies on SBC's impact on malaria knowledge, however, this category was further classified to capture different dimensions, including (1) knowledge that malaria is caused by mosquitos, (2) knowledge of the symptoms of malaria, (3) knowledge of malaria treatments, and (4) knowledge that ITNs work to prevent malaria.

A separate process was used to identify literature that would link intermediate determinants to behavioral outcomes. First, each study from the review process described above with intermediate outcomes was reviewed to ascertain whether the analysis also examined outcomes as a function of intermediate variables. Second, a PubMed search was conducted to capture studies that predicted outcomes as a function of intermediate determinants that would not have been identified in the other searches because they did not focus on SBC interventions. A total of 513 abstracts were identified, 61 of which were selected for a full-text review, and of these 35 had data extracted.

Among the malaria behavioral outcomes represented in the literature, there were sufficient data to build model pathways for two: ITN use and care seeking for fever and treatment adherence as part of case management of uncomplicated malaria. Box 1 describes the data limitations for also examining IPTp and the need for more research in this area.

When exploring the relationships between SBC interventions, intermediate determinants, and behavioral outcomes, we examined the ORs, which were either reported in the study or calculated from data presented

\section{BOX 1 WHAT ABOUT INTERMITTENT PREVENTIVE TREATMENT IN PREGNANCY?}

The use of IPTp is an important malaria preventive behavior that SBC can influence. As such, we initially aimed to model IPTp in addition to ITN use and case management. The literature extraction yielded 27 studies with indirect (SBC impact on IPTp use through intermediate determinants) or direct (SBC impact on IPTp use) links for one or more of the different SBC intervention/outcome combinations in the effectiveness database. To connect these links, we needed at least three observations examining the same SBC intervention type and evaluating the same determinants or outcomes. For IPTp, there were too few observations in most links to build a model that could adequately capture SBC's impact on IPTp use. This exercise highlighted key research questions that, if addressed, could further understanding on how SBC influences IPTp use. These are included in the Discussion section. 
in the manuscript. Box $\mathbf{2}$ explains how ORs represent the impact of SBC programming. Each study's impact observation was categorized by SBC intervention and determinant or outcome type. The median OR was then used to model the pathway between the links. Appendix A provides further methodological details on how the median ORs were derived.

\section{BOX 2 UNDERSTANDING ODDS RATIOS}

ORs are on a log scale where an OR less than 1.0 implies a negative relationship between the SBC intervention and a positive change in the determinant/outcome; a ratio greater than 1.0 implies a positive relationship between the SBC intervention and a positive change in the determinant/ outcome. For example, a radio show that aims to improve knowledge that ITNs prevent malaria with an $\mathrm{OR}=2.0 \mathrm{implies}$ that those exposed to the show have twice the odds of having this knowledge compared to those not exposed.

The magnitude of the impact of any intervention depends not only on the OR but also on the baseline levels (i.e., what percentage of the population already has this knowledge) and the change in coverage (i.e., how many people are reached who do not already have the characteristic of interest).

\section{SBC impact on ITN use}

Sleeping under an ITN has been found to be highly effective in preventing malaria, reducing transmission, and reducing malaria mortality 9 . SBC increases ITN use by increasing access to ITNs among those with insufficient access and increasing use among those with sufficient access. "Access" is typically measured as a household having at least one ITN for every two people. ${ }^{10}$ SBC is a component of most ITN distribution campaigns and focuses on making households more receptive to receiving, using, and maintaining ITNs through increasing their knowledge about malaria transmission, improving selfefficacy around ITN use, and promoting the perceived value of ITNs and their regular use.

Table 2 details the median ORs related to pathways for ITN use. The ORs are only reported where there was sufficient evidence to model a link between two variables.
Note that not all SBC interventions have linkages to the intermediate determinants. Where linkages through intermediate outcomes are lacking, the direct linkage between SBC interventions and ITN use represents the relationship. Where intermediate pathways are present, the direct linkage captures the residual impact.

\section{TABLE 2 MEDIAN ORS FOR ITN USE}

\begin{tabular}{|c|c|c|}
\hline & $\begin{array}{c}\# \\
\text { STUDIES }\end{array}$ & $\begin{array}{c}\text { MEDIAN } \\
\text { OR }\end{array}$ \\
\hline \multicolumn{3}{|l|}{ LINK 1: SBC TO INTERMEDIATE OUTCOMES } \\
\hline IPC \& knowledge mosquitoes cause malaria & 6 & 3.22 \\
\hline IPC \& knowledge that ITNs work & 6 & 2.21 \\
\hline IPC \& positive attitudes on ITNs & 3 & 1.27 \\
\hline Mass media \& positive attitudes on ITNs & 3 & 2.88 \\
\hline $\begin{array}{l}\text { Packages }{ }^{*} \& \text { knowledge mosquitoes cause } \\
\text { malaria }\end{array}$ & 6 & 1.54 \\
\hline Packages \& knowledge that ITNs work & 4 & 2.01 \\
\hline Packages \& positive attitudes on ITNs & 5 & 3.08 \\
\hline Packages \& communication about ITNs & 3 & 6.06 \\
\hline \multicolumn{3}{|c|}{ LINK 2: INTERMEDIATE OUTCOMES TO ITN ACCESS OR USE } \\
\hline $\begin{array}{l}\text { Knowledge mosquitoes cause malaria \& } \\
\text { ITN access }\end{array}$ & 2 & 2.07 \\
\hline $\begin{array}{l}\text { Knowledge mosquitoes cause malaria \& } \\
\text { ITN use }\end{array}$ & 12 & 1.79 \\
\hline Knowledge that ITNs work \& ITN access & 2 & 1.60 \\
\hline Knowledge that ITNs work \& ITN use & 11 & 1.55 \\
\hline Positive attitudes on ITNs \& ITN access & 3 & 1.94 \\
\hline Positive attitudes on ITNs \& ITN use & 11 & 1.87 \\
\hline $\begin{array}{l}\text { Communication between individuals and } \\
\text { family, friends, or others about ITNs \& ITN } \\
\text { use }\end{array}$ & 5 & 1.56 \\
\hline \multicolumn{3}{|l|}{ LINK 3: SBC TO ITN ACCESS OR USE } \\
\hline IPC \& ITN access & 4 & 2.84 \\
\hline IPC \& ITN use & 16 & 1.95 \\
\hline Mass media \& ITN access & 4 & 2.77 \\
\hline Mass media \& ITN use & 9 & 1.53 \\
\hline Packages \& ITN access & 9 & 4.46 \\
\hline Packages \& ITN use & 21 & 2.25 \\
\hline \multicolumn{3}{|l|}{ LINK BETWEEN ITN ACCESS AND USE } \\
\hline ITN access \& ITN use & 4 & 2.81 \\
\hline
\end{tabular}

*Packages are groups of SBC interventions, including any combination of mass and digital media, IPC, provider behavior change, and community engagement where the study does not differentiate impact by intervention type but at the level of the broader "package." 
Overall, the evidence shows that SBC interventions are effective in improving ITN access and use, both directly and through the intermediate determinants modeled here based on availability in the literature. Half of the available intermediate determinant observations were focused on knowledge and the other half on attitudes and communication. The strongest relationship between SBC interventions and intermediate determinants was for SBC packages and communication about ITNs with family, friends, or others. For example, when these interventions were present, the odds of a communication about malaria with friends, family, and/or others was six times higher. SBC packages, which are typically more intensive and costly compared to mass media and IPC alone, also showed the strongest direct impact on ITN access and use.

\section{SBC impact on care seeking for fever and treatment adherence as components of case management of uncomplicated malaria}

Timely diagnosis and treatment of malaria are critical to reducing the morbidity and mortality associated with malaria. ${ }^{5}$ Several factors contribute to proper case management of malaria. Many SBC programs target barriers to prompt care seeking and adherence, including a lack of understanding on the cause and transmission of malaria, poor attitudes regarding self-efficacy to access malaria testing and treatment, and lack of belief in the efficacy of diagnostic tools and medications. ${ }^{11}$ SBC focuses on a wide range of determinants to improve timely care seeking for fever, diagnosis, and treatment, including knowledge, social support, norms, self-efficacy, attitudes, and communication. The literature was only sufficient to model the intermediate pathways through knowledge. In total, 38 studies contributed to the median ORs reflected in Table 3.

The studies found an overall positive relationship between SBC and knowledge, knowledge and care seeking and adherence, and SBC and care seeking and adherence. As with ITNs, the SBC packages had the strongest direct link to improvements in care seeking and adherence. Additionally, SBC packages had the highest OR to an intermediate determinant, which was knowledge of malaria symptoms. Among the three knowledge indicators found to influence care seeking
TABLE 3 MEDIAN ORS FOR FEVER CARE SEEKING AND TREATMENT ADHERENCE FOR UNCOMPLICATED MALARIA

\begin{tabular}{|c|c|c|}
\hline & $\begin{array}{c}\# \\
\text { STUDIES }\end{array}$ & $\begin{array}{l}\text { MEDIAN } \\
\text { OR }\end{array}$ \\
\hline \multicolumn{3}{|l|}{ LINK 1: SBC TO INTERMEDIATE OUTCOMES } \\
\hline IPC \& knowledge mosquitoes cause malaria & 6 & 3.22 \\
\hline IPC \& knowledge of malaria symptoms & 4 & 1.95 \\
\hline IPC \& knowledge of malaria treatment & 3 & 1.83 \\
\hline $\begin{array}{l}\text { Packages }{ }^{*} \& \text { knowledge mosquitoes cause } \\
\text { malaria }\end{array}$ & 6 & 1.54 \\
\hline Packages \& knowledge of malaria symptoms & 5 & 4.06 \\
\hline Packages \& knowledge of malaria treatment & 5 & 1.66 \\
\hline \multicolumn{3}{|c|}{$\begin{array}{l}\text { LINK 2: INTERMEDIATE OUTCOMES TO CARE SEEKING } \\
\text { FOR FEVER AND TREATMENT ADHERENCE }\end{array}$} \\
\hline $\begin{array}{l}\text { Knowledge mosquitoes cause malaria \& } \\
\text { case management }\end{array}$ & 3 & 1.05 \\
\hline $\begin{array}{l}\text { Knowledge of malaria symptoms \& case } \\
\text { management }\end{array}$ & 3 & 1.35 \\
\hline $\begin{array}{l}\text { Knowledge of malaria treatment \& case } \\
\text { management }\end{array}$ & 2 & 3.21 \\
\hline \multicolumn{3}{|l|}{$\begin{array}{l}\text { LINK 3: SBC TO CARE SEEKING FOR FEVER AND } \\
\text { TREATMENT ADHERENCE }\end{array}$} \\
\hline IPC \& case management & 6 & 1.33 \\
\hline Packages \& case management & 12 & 2.96 \\
\hline Mass media \& case management & 4 & 2.25 \\
\hline $\begin{array}{l}\text { Short message service (SMS) reminders \& } \\
\text { case management }\end{array}$ & 3 & 1.10 \\
\hline
\end{tabular}

*Packages are groups of SBC interventions, including any combination of mass and digital media, IPC, provider behavior change, and community engagement where the study does not differentiate impact by intervention type but at the level of the broader "package."

and adherence, knowledge of malaria treatment (e.g., the appropriate medication, where to seek treatment) had the highest increased odds of improved care seeking and adherence.

\section{Costs of malaria SBC interventions}

The literature on SBC costs was reviewed to obtain unit cost estimates. The original SBC cost search for the family planning business case identified 130 studies with SBC cost data related to health, including 9 SBC malaria cost studies. ${ }^{7}$ Building on this work, a supplemental literature review was conducted with additional malaria-specific keywords that identified 825 additional abstracts and 51 full-text reviews, which resulted in the inclusion of a 
further 22 studies. Appendix A provides further details on the methodology used for the SBC cost data search, data extraction, and analysis.

For each SBC intervention, median unit costs were calculated, as well as a range based on first and third quartiles. Unit cost data were included in the analysis of $\mathrm{SBC}$ intervention costs if they used one of the following units of measurement for the SBC intervention:

- Per person exposed-Used for mass media, typically represents one-way communication directed at individuals; measures in the cost literature indicating exposure include terms such as "people who listened to," "people who watched," or "people who subscribed to (a newspaper, magazine, etc.)."

- Per person participating-Used for IPC or packages of $\mathrm{SBC}$ interventions and indicates more interactive communication between SBC practitioners and individuals; measures in the cost literature indicating participation include terms like "people who received (counseling, etc.)," "people who visited/were visited by," or "people who took part in... ."

- Per person contacted-Used for mobile phone/text messages and reminders. These typically describe targeted one-way communication.

Table 4 displays the median unit costs and interquartile ranges for SBC activities relevant to the SBC interventions from the literature, which were used for modeling cost-effectiveness in Tanzania and Côte d'Ivoire. Unit costs for mass media are substantially lower due to different features of the interventions and the typically higher denominators used in calculating costs per person exposed. In contrast, costs per persons participating in IPC and intervention packages are generally higher given higher activity costs and relatively fewer people reached with these intervention types. Malaria-only SBC intervention costs were also examined to see if costs differed substantially for malaria compared to the other health areas contained; however, there were too few malaria-specific unit cost observations for each SBC intervention to use malaria median SBC costs.

In addition to the SBC costs, it is important to include the costs associated with increased utilization of ITNs and increases in fever care seeking and treatment. Table 5 displays the unit costs used for increased utilization of ITNs and fever care seeking and treatment, which were adjusted to 2019 US dollars (USD) to be comparable with the SBC costs. It was assumed that additional nets to
TABLE 4 MEDIAN UNIT COSTS FOR SBC INTERVENTIONS (2019 USD)

\begin{tabular}{|c|c|c|c|}
\hline INTERVENTION & \# STUDIES & MEDIAN & RANGE: Q1-Q3 \\
\hline \multicolumn{4}{|c|}{ PER PERSON EXPOSED } \\
\hline Radio & 11 & $\$ 0.27$ & $\$ 0.14-\$ 1.35$ \\
\hline Billboards/flyers & 5 & $\$ 0.26$ & $\$ 0.13-\$ 1.07$ \\
\hline Live drama & 5 & $\$ 0.47$ & $\$ 0.41-\$ 2.72$ \\
\hline \multicolumn{4}{|c|}{ PER PERSON PARTICIPATING } \\
\hline Group IPC & 29 & $\$ 459$ & $\$ 1.76-\$ 7.76$ \\
\hline Individual IPC & 16 & $\$ 8.71$ & $\$ 3.15-\$ 41.12$ \\
\hline Packages* of SBC & 4 & $\$ 23.46$ & $\$ 12.87-\$ 34.97$ \\
\hline \multicolumn{4}{|c|}{ PER PERSON CONTACTED } \\
\hline $\begin{array}{l}\text { Mobile phone/text } \\
\text { message reminders }\end{array}$ & 7 & $\$ 2.08$ & $\$ 1.32-\$ 2.56$ \\
\hline
\end{tabular}

*Packages are groups of SBC interventions, including any combination of mass and digital media, IPC, provider behavior change, and community engagement where the study does not differentiate impact by intervention type but at the level of the broader "package."

increase coverage would be procured at a ratio of one net for every 1.8 people, and each additional uncomplicated malaria case managed would be both diagnosed and treated with appropriate first-line malaria medication for confirmed cases only. The financial cost includes both the unit cost and the resources required for its delivery. The next section describes how these costs were incorporated into the final cost calculations.

\section{TABLE 5 UNIT COSTS ASSOCIATED WITH INCREASES IN ITN USE AND CASE MANAGEMENT}

\begin{tabular}{|llc|}
\hline UNIT COST & SOURCE & $\begin{array}{c}\text { MEDIAN COST } \\
\text { (2019 USD) }\end{array}$ \\
\hline $\begin{array}{llc}\text { Unit cost of ITN } \\
\text { Financial cost of malaria } \\
\text { diagnosis }\end{array}$ & $\begin{array}{l}\text { WMI 201912 } \\
\text { White et al., }\end{array}$ & $\$ 5.13$ \\
$\begin{array}{l}\text { Financial cost of uncomplicated } \\
\text { malaria case management }\end{array}$ & $\begin{array}{l}\text { White et al., } \\
2011^{13}\end{array}$ & $\$ 6.92$ \\
\hline
\end{tabular}

*Alternative unit costs for ITNs were examined, up to a maximum financial cost of $\$ 11.91$, with negligible effects on cost-effectiveness results. 


\section{Assessing Cost-effectiveness}

Modeling malaria SBC investments in an individual country can examine the implications for both cost and impact by combining both effectiveness and cost estimates in the form of an incremental cost-effectiveness ratio (ICER). For health interventions, a common ICER is to examine the cost per disability-adjusted life year (DALY) averted, which is the cost per one additional healthy year of life. The cost per DALY can be compared to the gross domestic product (GDP) per capita to benchmark against international standards for cost-effectiveness of health interventions, where a cost per DALY less than the GDP per capita is considered "highly cost-effective" and a cost per DALY between one and three times the GDP per capita is considered "cost-effective."14

The findings derived from the existing literature can be used to assess the cost-effectiveness of SBC for malaria in two ways. First, individual studies that have both effectiveness and cost results can be examined as case examples. Of the extracted malaria studies, few had both effectiveness results for an ITN use or case management outcome and sufficient costing data to examine cost-effectiveness. ${ }^{15-17}$ Box $\mathbf{3}$ details the cost-effectiveness results from a mass media campaign in Cameroon aimed to increase ITN use that was highly cost-effective. ${ }^{15}$

The second way is what we have done in this business case, using effectiveness and cost estimates from the literature to model malaria SBC investments in an individual country to generate an ICER for assessing cost-effectiveness. Two countries, Côte d'Ivoire and Tanzania, were selected as examples for this analysis for two primary reasons. First, in both countries the Spectrum Malaria model had previously been used to model their epidemic and interventions, so there were already calibrated model data files available, thus minimizing the need for additional time and resources to develop these inputs. Second, the countries provide a nice contrast because they differ in terms of geography, epidemic characteristics, and SBC scale and approaches.

Modeling the cost-effectiveness of SBC requires both modeling the impact of SBC interventions on malaria behaviors and subsequent health impacts as well as modeling the cost of SBC scale-up to generate the ICER

(Figure 2).

\section{BOX 3: COST-EFFECTIVE MASS MEDIA CAMPAIGN IN CAMEROON}

A 2012 national mass media intervention in Cameroon focused on improving the "net use culture" by increasing ITN use among households that already owned them. A large coalition of public and private partners implemented a national media campaign called "KO Palu," meaning "Knock Out Malaria." The campaign utilized the previously developed NightWatch platform, which had contributed to improved health behaviors by influencing knowledge and attitudes, providing reminders, and shaping social norms. One key feature of the campaign was an original song and music video performed by popular Cameroonian musicians that was played on local radio and television as well as via social media. Additional public service announcements featured local celebrities.

After the campaign, a population-based survey was conducted, and an analysis was performed to evaluate the impact of KO Palu. Controlling for other potential variables using propensity score matching, the study found that the campaign resulted in a $6.6 \%$ increase in ITN use for adults and a $12 \%$ increase among children in the previous night. Applied to the population, the authors conservatively estimated an increase of 298,650 adults and 221,000 children sleeping under an ITN. This increase in coverage translates to an estimated 15,000 DALYs averted or, in other words, an additional 15,000 healthy years of life for the population.

The KO Palu campaign cost \$842,966 from January 2011 to March 2012, which translated to costs of the program of $\$ 0.16$ per adult reached and $\$ 1.62$ per person protected. Adjusting for inflation, the campaign would result in an ICER of S64 (2019 USD) per DALY averted, well below Cameroon's per capita GDP threshold of \$1,778 for a highly cost-effective health intervention. 
FIGURE 2 MODELING COST-EFFECTIVENESS OF SBC INTERVENTIONS

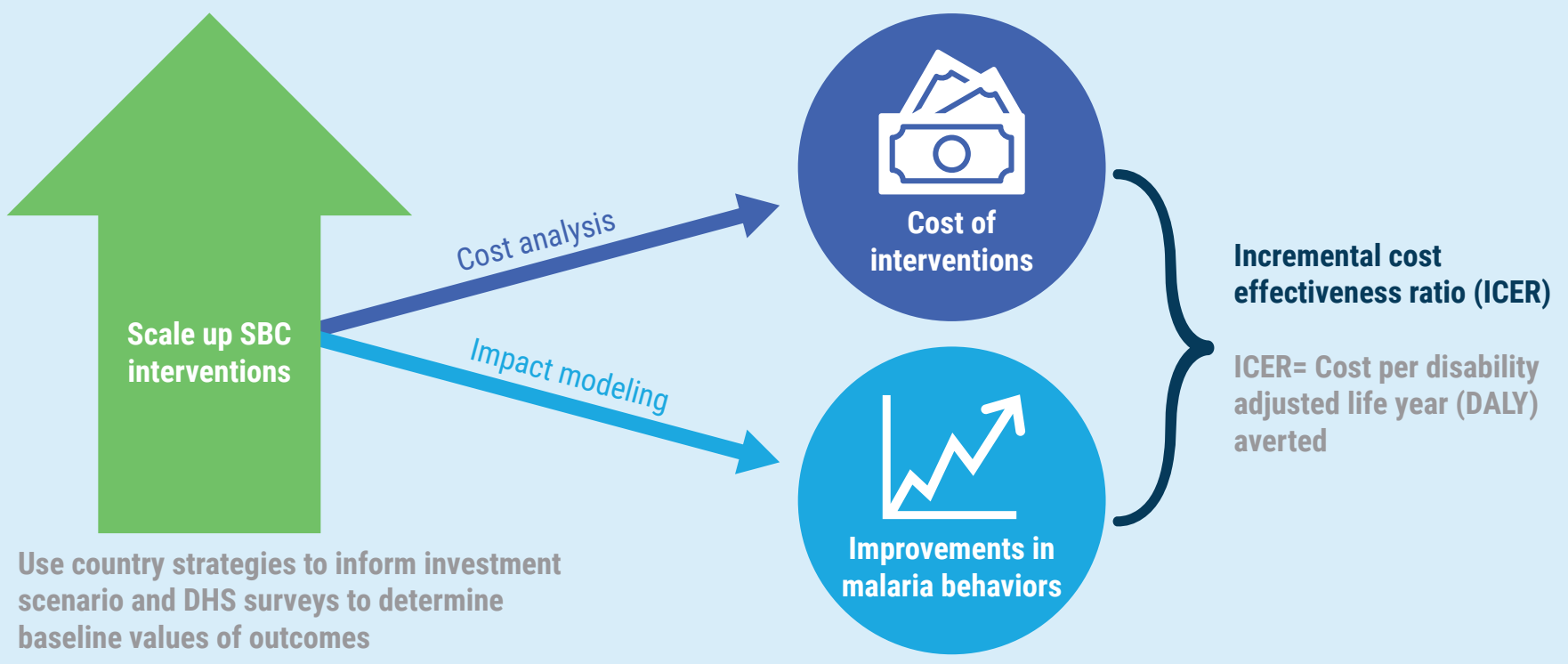

The impact modeling requires four key inputs:

- Median ORs on the impact pathways from SBC to malaria behaviors

- Baseline data on behavioral outcomes and intermediate determinants

- Investment in SBC interventions

- Population data by age group

Using these inputs, the impact of investing in SBC interventions on malaria behaviors is calculated both indirectly through the intermediate determinants and directly to obtain impact not captured by the intermediate determinants. The median OR for each SBC intervention is applied to those exposed, calculating the change in coverage at the national level for each outcome, accounting for the baseline level. This yields the resulting percentage point increase in the population that used ITNs the previous night and the percentage point increase in uncomplicated malaria cases managed appropriately. These percentage point increases are then input into the Spectrum Malaria model from 2019 to 2023 , which produces the number of corresponding lives saved and malaria cases averted due to the increase in coverage when compared with a business-as-usual scenario where coverage levels remain constant. The results are disaggregated by age group (under 5 years, 5 to 14 , and 15 plus).

Impact projections in the Spectrum Malaria model reflect population-dynamic effects over the short and long term, including shifts in endemicity, acquired immunity, and cohort effects resulting when interventions lower malaria transmission. The model applies statistical impact functions as proportional burden reductions, rather than absolute predicted post scale-up burden levels. To not overestimate impact in the first and second years of coverage scale-up, the impact of any coverage change applies with a one-year lag and the impact of SBC interventions are assumed to last for one year. Further details of the Spectrum Malaria model are documented elsewhere. ${ }^{18}$

Next, the number of DALYs associated with SBC are calculated. DALYs represent the number of years of healthy life lost due to premature death or ill health. If you avert one DALY, you are adding an additional year of healthy life. DALYs are made up of years of life lost due to premature death and years lived with disability or ill health. We calculate each using the deaths and cases averted from Spectrum. The years of life lost averted are calculated by multiplying the deaths averted in each age group by the average years of life lost due to malaria for that age group (from Global Burden of Disease [GBD] 2019). The years lived with disability or ill health averted are calculated by multiplying the cases averted by the disability weight for malaria (GBD 2019) and the average duration of an episode. These calculations do not use age weighting or discounting, in alignment with the GBD project.

To calculate the total costs associated with SBC investment scenarios, we use the unit costs for each type of SBC intervention implemented in Tanzania or Côte 
$d^{\prime}$ Ivoire and multiply them by the number of persons exposed to or participating in the interventions per year. In addition to the unit costs of SBC, the comprehensive unit costs used for calculating the ICER also take into consideration the increased direct costs associated with obtaining additional ITNs (assuming one net per 1.8 people) and treating additional cases. This includes the financial cost of both diagnosis and case management of uncomplicated malaria from the systematic review by White et al. (2011), ${ }^{13}$ converted to 2019 USD, as well as the cost of ITNs.

To calculate the ICERs (cost per DALY averted), the total costs are divided by the DALYs averted.

\section{Modeling SBC cost-effectiveness in Tanzania}

\section{Country context}

Approximately $3 \%$ of all malaria cases and $5 \%$ of malaria deaths worldwide occur in Tanzania. ${ }^{19}$ Recent malaria control efforts have made remarkable progress in malaria prevention and have resulted in substantial decreases in childhood mortality..$^{20}$ As of 2018 , the national malaria incidence in Tanzania was 124.3 per 1,000 population at risk, with $100 \%$ of the country considered at risk. ${ }^{21}$ As a priority country for malaria, PMI supports the Government of Tanzania in the deployment of a comprehensive package of interventions, including ITNs, IRS, rapid diagnostic tests, artemisinin-based combination therapy ( $A C T)$, and the training of health workers on malaria prevention and treatment. ${ }^{22}$ SBC interventions, which enhance the effectiveness of other interventions by generating increased demand for malaria prevention and treatment and which are implemented as part of the Tulonge Afya project, are also an important component of this package.

\section{Baseline data}

For both countries, modeling was completed for a fiveyear period with a baseline year of 2018 and scale-up of SBC interventions from 2019 to 2023. Baseline data for Tanzania were obtained from three primary sources: (1) the 2017 Tanzania Malaria Indicator Survey (TMIS), ${ }^{23}$ (2) the Tulonge Afya baseline report, ${ }^{24}$ and (3) modeling for the Global Fund using the Spectrum Malaria model. ${ }^{25}$ The resulting malaria indicators and outcomes are found in Table 6.
TABLE 6 TANZANIA BASELINE MODEL PARAMETERS

\begin{tabular}{lll} 
& $\begin{array}{c}\text { BASELINE } \\
\text { VALUE }\end{array}$ & \multicolumn{1}{c}{ SOURCE } \\
\hline MALARIA INDICATORS AND OUTCOMES \\
ITN access
\end{tabular}

'Access to an ITN is measured by the proportion of the population that could sleep under an ITN if each ITN in a household were used by 2 people.

iiITN use is defined as percentage of the population who reported sleeping under an ITN the previous night.

iiïffective management of uncomplicated malaria is defined as fever care seeking and adherence to and completion of a full course of a recommended treatment with a good-quality antimalarial medication.

\section{Investment scenario}

To assess a realistic investment scenario, the following sources were examined to determine the types and scale-up patterns of SBC interventions planned:

- The Tulonge Afya annual $(2018,2019)$ and quarterly (Q1 2020) reports ${ }^{26-28}$

- The Tanzania PMI malaria operational plans for 2019 and $2020^{29,30}$

- The Global Fund Kiungo cha Mabadiliko ya Kutokomeza Ugonjwa wa Malaria Project 2019 annual and January-June 2020 semiannual report ${ }^{31,32}$

Based on a review of these documents, an initial SBC investment scenario was created for 2019 to 2023. The total SBC costs were calculated by multiplying the unit costs from the literature and the total expected reach of SBC programming based on the programmatic reports listed above and summarized in Table 7, which details 
TABLE 7 ANNUAL REACH FOR SBC INTERVENTIONS IN TANZANIA

\begin{tabular}{|lcc|}
\hline SBC INTERVENTION & $\begin{array}{c}\text { REACH FOR ITN } \\
\text { ACCESS \& USE }\end{array}$ & $\begin{array}{c}\text { REACH FOR CASE } \\
\text { MANAGEMENT }\end{array}$ \\
\hline Individual IPC & 30,000 & - \\
\hline Group IPC & 580,000 & 310,000 \\
Radio & $17,500,000$ & $9,500,000$ \\
Billboards/flyers & 100,000 & 100,000 \\
Live drama/road shows/ & $1,430,000$ & $1,4300,000$ \\
mini events & & 60,000 \\
\hline Mobile/text reminders & - & \\
\hline
\end{tabular}

the annual SBC activities, with program initiation in 2019 and wind-down in 2023. Over five years, the total costs for SBC for this scenario are estimated at $\$ 43.2$ million in 2019 USD. Tanzania's SBC program integrates messaging across multiple health areas (e.g., malaria, family planning, maternal and child health), which likely captures considerable efficiencies and thus lowers unit costs. The unit costs used here do not reflect those efficiencies, and data are not available at present to inform alternative unit costs for integrated SBC. As such, the total costs for SBC in Tanzania may be substantially lower than are modeled here. In addition to SBC costs, the modeled increase in ITN access and case management would require an additional \$22 million in ITN and health care costs.

\section{Results}

Based on this investment scenario, there is an expected 4.8 percentage point increase in the proportion of the population sleeping under an ITN and a 3.7 percentage point increase in uncomplicated malaria cases that are appropriately managed. Since the interventions are maintained for each of the five years, this behavior improvement is also maintained for each of the five years (Figure 3). When modeled in Spectrum Malaria, over five years these improved behaviors result in approximately 6.8 million malaria cases averted and 7,763 deaths averted, a third among children under 5 years.

Factoring in the total costs and total DALYs associated with averted cases and deaths, the costs per DALY averted are \$269 for ITN use, \$101 for case management, and $\$ 124$ for the combination of the two, as shown in Figure 4. The sensitivity analysis calculates the results using the first and third quartile unit costs from the interquartile range. The entire range of costs are far below the Tanzania GDP per capita benchmark of $\$ 1,154$ for a highly cost-effective intervention.

\section{FIGURE 3 ANNUAL CHANGE IN BEHAVIOR DUE TO SBC INTERVENTIONS IN TANZANIA}

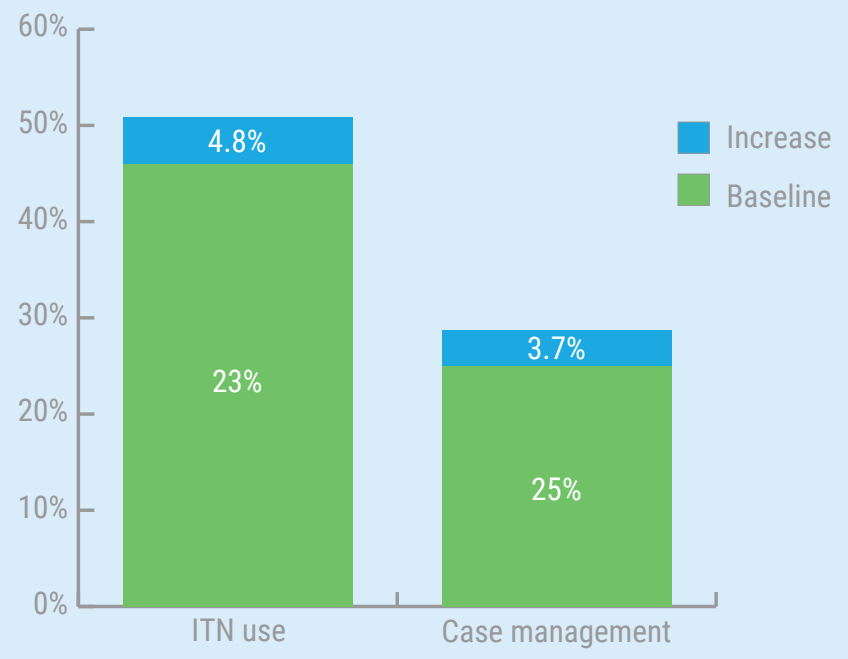

Note: ITN use-percentage slept under an ITN the previous night; case management-percentage of malaria cases treated appropriately

\section{FIGURE 4 COST PER DALY AVERTED BY SBC} INTERVENTIONS IN TANZANIA

\section{$\$ 1200 \quad$ Highly cost effective benchmark for Tanzania}

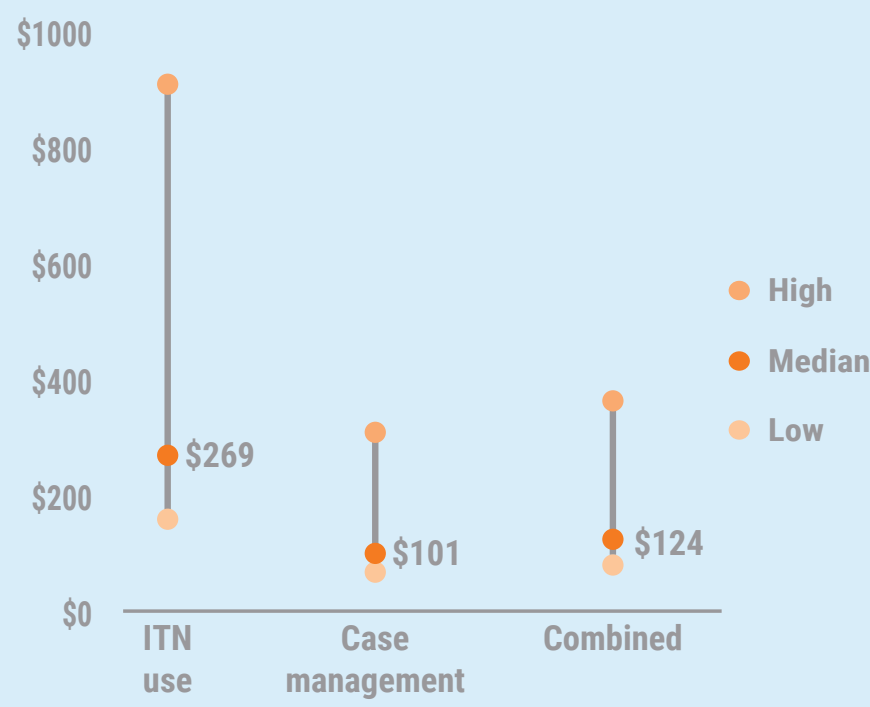

\section{Modeling SBC cost-effectiveness in Côte d'Ivoire}

\section{Country context}

Approximately $2 \%$ of all malaria deaths worldwide occur in Côte d'Ivoire, and it has the fifth highest number of cases globally. ${ }^{18}$ The malaria incidence in Côte d'Ivoire is 
331 per 1,000 at risk, with $100 \%$ of the country considered at risk year round. ${ }^{21}$ Malaria mortality is primarily among children under 5 in Côte d'Ivoire, and it is the largest cause of death in this age group. ${ }^{33} \mathrm{PMI}$ supports the government of Côte d'Ivoire's efforts to increase ITN use, malaria case management, and IPTp use. ${ }^{33}$ SBC interventions aim to support these health behaviors by improving knowledge, attitudes, and communication around malaria.

\section{Baseline data}

The baseline data for Côte d'Ivoire are shown in Table $\mathbf{8}$, based on the 2019 World Malaria Report, ${ }^{19}$ modeling conducted by the Malaria Atlas Project and Avenir Health for the Programme Nationale de Lutte contre le Paludisme (PNLP, the national malaria control program) using the Spectrum Malaria model, ${ }^{34}$ and the 2018 Breakthrough ACTION Malaria Behavior Survey. ${ }^{35}$

\section{TABLE 8 CÔTE D'IVOIRE BASELINE MODEL PARAMETERS}

\begin{tabular}{|c|c|c|}
\hline \multicolumn{3}{|c|}{$\begin{array}{l}\text { BASELINE } \\
\text { VALUE }\end{array}$} \\
\hline \multicolumn{3}{|c|}{ MALARIA INDICATORS AND OUTCOMES } \\
\hline ITN access & $80 \%$ & $\begin{array}{l}2019 \text { World Malaria } \\
\text { Report }\end{array}$ \\
\hline ITN use & $63 \%$ & $\begin{array}{l}\text { Spectrum Malaria } \\
\text { modeling for PNLP }\end{array}$ \\
\hline Case management & $54 \%$ & $\begin{array}{l}\text { Spectrum Malaria } \\
\text { modeling for PNLP }\end{array}$ \\
\hline \multicolumn{3}{|l|}{ INTERMEDIATE OUTCOMES } \\
\hline $\begin{array}{l}\text { Knowledge that mosqui- } \\
\text { toes cause malaria }\end{array}$ & $91 \%$ & $\begin{array}{l}2018 \text { Malaria Behavior } \\
\text { Survey }\end{array}$ \\
\hline $\begin{array}{l}\text { Knowledge of malaria } \\
\text { symptoms }\end{array}$ & $80 \%$ & $\begin{array}{l}2018 \text { Malaria Behavior } \\
\text { Survey }\end{array}$ \\
\hline $\begin{array}{l}\text { Knowledge of malaria } \\
\text { treatment }\end{array}$ & $40 \%$ & $\begin{array}{l}2018 \text { Malaria Behavior } \\
\text { Survey }\end{array}$ \\
\hline Knowledge that ITNs work & $84 \%$ & $\begin{array}{l}2018 \text { Malaria Behavior } \\
\text { Survey }\end{array}$ \\
\hline Positive attitudes on ITNs & $91 \%$ & $\begin{array}{l}2018 \text { Malaria Behavior } \\
\text { Survey }\end{array}$ \\
\hline $\begin{array}{l}\text { Communication about ITNs } \\
\text { with friends and family }\end{array}$ & $25 \%$ & $\begin{array}{l}2018 \text { Malaria Behavior } \\
\text { Survey }\end{array}$ \\
\hline
\end{tabular}

\section{Investment scenario}

Two main data sources were used to inform the initial investment scenario for Côte d'Ivoire. First, the 2019 and 2020 malaria operational plans were used to gauge overall budgets and SBC activities. ${ }^{36,37}$ Second, since Breakthrough ACTION is the primary USAID-funded implementing partner for malaria SBC in Côte d'Ivoire, the Breakthrough ACTION quarterly report to USAID was examined to ascertain intervention reach in the past year. ${ }^{38}$ The Global Fund also works in Côte d'Ivoire on malaria SBC; however, no documents were identified that specified Global Fund reach and SBC interventions. As such, we assumed the same level and type of SBC engagement, thus doubling the PMI annual budget and reach.

These documents enabled the formulation of an initial annual SBC investment scenario from 2019 to 2023 shown in Table 9. This investment scenario generates a five-year SBC cost of approximately $\$ 16.8$ million and an additional $\$ 12$ million for the costs of additional ITNs and case management, including the unit cost of commodities and the resources required for their delivery.

\begin{tabular}{|c|c|c|}
\hline SBC INTERVENTION & $\begin{array}{l}\text { REACH FOR ITN } \\
\text { ACCESS \& USE }\end{array}$ & $\begin{array}{l}\text { REACH FOR CASE } \\
\text { MANAGEMENT }\end{array}$ \\
\hline Group IPC & 120,000 & 120,000 \\
\hline Radio & $3,000,000$ & $3,000,000$ \\
\hline Packages & 50,000 & 50,000 \\
\hline
\end{tabular}

\section{Results}

There is an expected 1.5 percentage point increase in the population sleeping under an ITN and a 3.5 percentage point increase in uncomplicated malaria cases that are appropriately managed based on this investment scenario (Figure 5). When modeled in Spectrum Malaria, these improved behaviors result in over 1.2 million cases averted and 5,291 deaths averted, most of which are deaths among children under 5 .

When connecting the total costs and total DALYs associated with averted cases and deaths, the costs per DALY averted are \$261 for ITN use, \$57 for case management, and $\$ 63$ for the interventions combined, as shown in Figure 6. These are far below the Côte d'Ivoire GDP per capita benchmark of $\$ 2,023$ for a highly cost-effective intervention. 
FIGURE 5 ANNUAL CHANGE IN COVERAGE DUE TO SBC INTERVENTIONS IN CÔTE D'IVOIRE

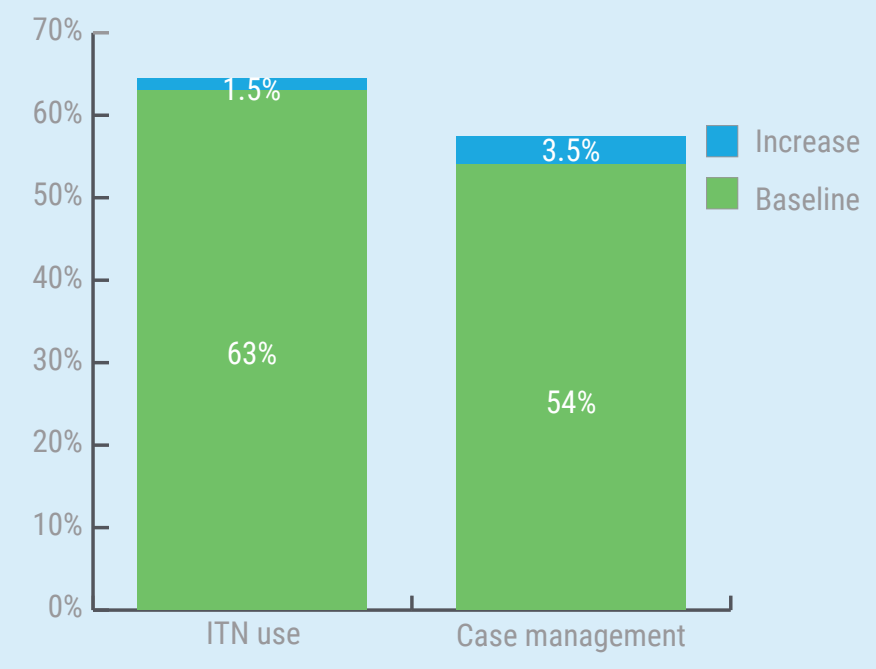

FIGURE 6 COST PER DALY AVERTED BY SBC INTERVENTIONS IN CÔTE D'IVOIRE

Highly cost effective benchmark for Côte d'Ivoire

$\$ 2000 \quad$ for Côte dilvoire

$\$ 1500$

$\$ 1000$

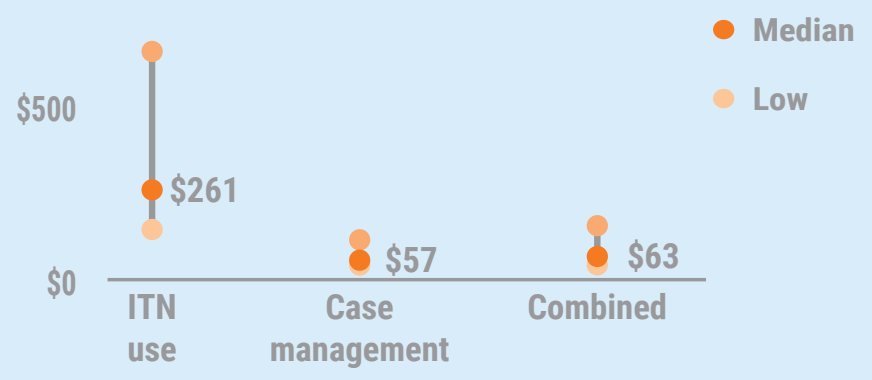




\section{Discussion}

\section{Cost-effectiveness of SBC programming}

The creation of the SBC business case for malaria and the resulting cost-effectiveness estimates reveal several interesting findings. First and foremost, the results provide evidence that SBC interventions are effective in improving malaria behaviors and that investments in SBC can be a cost-effective means of reducing the mortality and morbidity associated with malaria. In both the case study for Cameroon and the country modeling in Tanzania and Côte d'Ivoire, the initial scenario showed costs per DALY averted far below the national GDP per capita, the WHO benchmark for highly cost-effective interventions. The case example of the mass media campaign in Cameroon found a cost per DALY averted of $\$ 64$, which is quite close to the $\$ 63$ per DALY averted in Côte d'Ivoire. ${ }^{15}$ In contrast, the Tanzania estimate was $\$ 124$ cost per DALY averted, still far below the threshold for highly cost-effective interventions. Comparing these findings to other malaria cost-effectiveness studies in the literature is challenging because the costs per DALY averted reported in the literature vary widely based on the intervention, study methodology, and expression of results. A 2017 systematic review of 40 studies with measures of cost-effectiveness on malaria interventions found a range of cost per DALY averted from $\$ 1$ to $\$ 639.39$ The findings from this business case are clearly in this range.

While the cost-effectiveness findings for these investment scenarios indicate that they are highly cost-effective, there are additional reasons to expect that malaria SBC is even more cost-effective than presented in these results. One important reason is that these results do not capture the efficiencies of integrated SBC programming, where SBC messaging influences more than one health behavior. This is particularly relevant in the cost-effectiveness results for Tanzania, which has an integrated program. In Tanzania, the reach of SBC interventions in the investment scenarios was obtained through document review from implementing partners, and the unit costs from the literature were applied to the reach, generating an annual cost that far exceeded the PMI and Global Fund budgets for malaria SBC. As such, the unit costs applied in the model application are likely substantially higher than the actual unit costs for implementation in Tanzania, where implementers can leverage SBC funding from other health areas and take advantage of the cost-effectiveness synergies of integrated SBC programming. Additionally, there are other benefits to malaria SBC not being captured in the cost per DALY measure, such as a reduction in school absenteeism and health impact associated with intermediate determinants not yet included in the model due to the limited literature base.

As seen in the SBC unit costs, the cost per person exposed to mass media is far less than the cost per person participating in IPC and other more intensive interventions. While the impact of more intensive interventions is typically greater than mass media, the magnitude of the difference in impact is less than the difference in cost. When reviewing these factors, one should not conclude that a focus on mass media investments alone is the preferred strategy based solely on the low costs. While highly cost-effective, mass media are limited in their impact to the "low-hanging fruit" of those with both access to mass media and barriers that can be overcome through one-way communication, such as improving knowledge and awareness of where to access malaria prevention. Change in ideational factors due to mass media approaches beyond knowledge and awareness is difficult to measure, and knowledge levels are already high in many places. More recent SBC interventions have focused on more complex determinants of behavior, such as risk perception, self-efficacy, and response efficacy.

From an equity lens, programs would also want to consider in-person programming for those without access to mass media, particularly since those living in rural areas are at greater risk for malaria and often have not as readily adopted malaria prevention and treatment behaviors, requiring more intensive SBC focus. For these reasons, it is important to focus on the cost-effectiveness of a broader multichannel SBC program, which has been shown to be able to address multiple determinants of malaria behavior change. ${ }^{40}$

Similarly, while the intermediate pathways to impact focus largely on improving malaria knowledge, this is a function of the available literature and not necessarily 
the most important intermediate determinant to focus on. The baseline data show that there are already quite high levels of malaria knowledge and positive attitudes about ITNs in Tanzania and Côte d'Ivoire; however, there are likely other attitudinal elements around ITNs and case management that have not been captured in the model due to an insufficient literature base, such as self-efficacy to obtain treatment and social norms. For example, one study found that those who thought using ITNs was a norm in the community were nearly three times as likely to sleep under an ITN themselves. ${ }^{41}$ A further understanding of how SBC can influence these types of beliefs, norms, and attitudes would allow for a more nuanced and complete model of SBC and its impact on intermediate determinants of malaria behaviors, but more research is needed to build these pathways.

\section{Limitations}

In addition to knowledge gaps on SBC and malaria, there are other important limitations of the analysis to acknowledge. As with all modeling, the business case results are only as good as the model baseline parameters and assumptions. The inputs for some of the baseline parameters on existing levels of knowledge and attitudes are estimated based on proxy variables from survey data measuring similar concepts but are not an exact match. Additionally, the malaria SBC model relies on the median effectiveness and costs and thus does not account for a particularly innovative or inexpensive SBC intervention, which may yield better cost-effectiveness results. As discussed above, this may have important implications for integrated SBC programs. Further, the investment scenarios presented in this business case are based on documentation of malaria budgets, plans, and current activities to represent realistic investment scenarios, but they do not presume to perfectly capture the SBC currently being conducted in these countries. As such, these results are meant to be illustrative of the likely cost-effectiveness ratios if these SBC investments were undertaken. In the future, a more detailed engagement with country partners could allow for a more specified application that would better reflect the actual SBC efforts under way in a particular country.

For ITN use, one SBC-related outcome of interest is the use-to-access ratio (use:access), which assesses the degree that those with sufficient access to ITNs use them. The gap between access and use is expected to shrink because of SBC, where individuals are influenced to use the ITNs that they possess. However, the malaria SBC model does not adequately capture this dynamic because it assumes SBC interventions are focused on both access and use, and thus both access and use are estimated to increase due to SBC. Going forward, more details on the primary objectives of malaria SBC can help refine this relationship and explore this dynamic further.

A final important limitation of the malaria SBC model is that it only synthesizes the literature around SBC interventions and does not examine the effectiveness of malaria interventions without SBC. As such, one cannot examine the relative cost-effectiveness of a package of interventions with and without SBC.

\section{Research gaps}

Four important research gaps were identified in the creation of this business case. First, there are limited findings on the effectiveness of SBC on IPTp acceptance, as highlighted in Box 1. Studies that examine the direct link between SBC exposure and IPTp acceptance would allow for the inclusion of an important direct link in the model. Studies that link SBC interventions to improved knowledge about IPTp among pregnant women would also be useful, as there was sufficient literature to model that women with knowledge of IPTp had more than twice the odds of accepting IPTp compared to those without knowledge of IPTp. ${ }^{42,43}$ For the IPTp intervention, which is delivered through antenatal care visits during pregnancy, there is also a need to examine broader knowledge, attitudes, and norms around pregnancy and maternal health services that may require malaria SBC activities to be integrated with other SBC focus areas to raise IPTp rates.

Second, there is little research on the duration of effectiveness of SBC interventions in a population. Without research to justify a longer time frame, the current model assumes that SBC interventions impact behavior within the year they are implemented but not beyond that. As such, the modeled behavior change does not accumulate over the five years, even if interventions are shifting to new areas. If new evidence suggested that SBC interventions had longer durability, the expected impact and cost-effectiveness would be even greater.

Third, there are limitations to the SBC cost data for malaria. While efforts were made to standardize costs across studies, there is heterogeneity in the methodologies used, as well as poor intervention descriptions, 
making categorization challenging. Malaria SBC costs in particular contain many gaps, and thus malaria-specific SBC costs were not available. Consultations with SBC practitioners in country and further high-quality research on malaria SBC costs would help to validate or adjust the current SBC unit costs for greater precision.

Although SBC interventions in malaria have moved beyond focusing primarily on knowledge to addressing a wide variety of other intermediate determinants (e.g., perceptions of response efficacy of diagnostic tools and treatment/medications, self-efficacy, and social support), the literature base is still dominated by knowledge. More research is needed to better understand the relationship between SBC and intermediate determinants beyond knowledge. This would enable a model that more accurately reflects SBC programming being implemented at present.

In addition, there is a need for more research on other types of SBC interventions, such as provider behavior change, social media, and integrated SBC platforms. These are areas in need of more research to fully understand their impact on important health behaviors. ${ }^{44}$ 


\section{Conclusions}

The findings from this research examining the cost-effectiveness of malaria SBC consistently found that malaria SBC can be highly cost-effective, even in different epidemiological settings. As such, the findings here can be used to help advocate for maintaining or increasing malaria SBC funding. Looking forward, the malaria SBC model can be improved upon as future research helps to fill knowledge gaps on malaria SBC effectiveness and costs. 
1. USAID. 2016. "USAID social and behavior change programs for ending preventable child and maternal deaths." Washington, DC: USAID. https://www.usaid.gov/sites/default/files/documents/1864/SBC-EPCMD-WhitePaper_webready-508.pdf.

2. USAID. 2018. Social and behavior change. https://www. usaid.gov/what-we-do/global-health/cross-cutting-areas/ social-and-behavior-change.

3. Rosen, J. E. et al. 2019. "The business case for investing in social and behavior change for family planning." Breakthrough RESEARCH. Washington, DC: Population Council.

4. World Malaria Report 2020. 2020. Geneva: World Health Organization. https://www.who.int/teams/global-malaria-programme/reports/world-malaria-report-2020, Accessed January 5, 2021.

5. Centers for Disease Control and Prevention. 2018. https:// www.cdc.gov/malaria/malaria_worldwide/reduction/index. html. Accessed August 13, 2020.

6. Breakthrough ACTION. 2020. "About the malaria database" [Internet]. https://behaviorchangeimpact.org/malaria-landing-page/. Accessed August 13, 2020.

7. Avenir Health. "Documenting the costs of social behavior change interventions for health in low- and middle-income countries." Forthcoming.

8. RBM Partnership to End Malaria. 2018. "The strategic framework for malaria social and behavior change communication 2018-2030." RBM Partnership to End Malaria. https://www. pmi.gov/docs/default-source/default-document-library/ tools-curricula/framework-for-malaria-social-and-behavior-change-communication-2018-2030-english.pdf

9. Fullman, N. et al. 2013. "Nets, spray or both? The effectiveness of insecticide-treated nets and indoor residual spraying in reducing malaria morbidity and child mortality in sub-Saharan Africa," Malaria Journal 12: 62. doi: 10.1186/1475-2875-12-62

10. Koenker, H., E. Ricotta, B. Olapeju, and I. Choiriyyah. 2018. "Insecticide-treated nets (ITN) access and use report." Baltimore, MD: PMI | VectorWorks Project, Johns Hopkins Center for Communication Programs.

11. Maslove, D. M. et al. 2009. "Barriers to the effective treatment and prevention of malaria in Africa: A systematic review of qualitative studies," BMC International Health and Human Rights 9: 26. doi: 10.1186/1472-698X-9-26

12. USAID and US President's Malaria Initiative (PMI). 2019. US President's Malaria Initiative FY 2020 Guidance. Washington, DC: PMI. https://www.pmi.gov/docs/default-source/ default-document-library/tools-curricula/pmi-technical-guidance-(march-2016).pdf

13. White, M. T., L. Conteh, R. Cibulskis, and A. C. Ghani. 2011. "Costs and cost-effectiveness of malaria control interventions-a systematic review," Malaria Journal 10: 337. doi: 10.1186/1475-2875-10-337
14. WHO Commission on Macroeconomics and Health. 2001. Macroeconomics and health: investing in health for economic development. Geneva: WHO. https://apps.who.int/iris/ handle/10665/42435

15. Bowen, H. L. 2013. "Impact of a mass media campaign on bed net use in Cameroon," Malaria Journal 12: 36. doi: 10.1186/1475-2875-12-36

16. Kilian, A. et al. 2015. "The effect of single or repeated home visits on the hanging and use of insecticide-treated mosquito nets following a mass distribution campaign-A cluster randomized, controlled trial," PLOS ONE 10(3): e0119078. doi: 10.1371/journal.pone.0119078

17. Das, A. et al. 2015. "Strengthening malaria service delivery through supportive supervision and community mobilization in an endemic Indian setting: An evaluation of nested delivery models," Malaria Journal 13: 482. doi: 10.1186/1475-2875-13-482

18. Hamilton, M. et al. 2017. "Spectrum-Malaria: A userfriendly projection tool for health impact assessment and strategic planning by malaria control programmes in sub-Saharan Africa," Malaria Journal 16: 68. doi: 10.1186/ s12936-017-1705-3

19. World Health Organization. 2019. World Malaria Report 2019. Geneva: World Health Organization. https://www.who.int/ publications/i/item/9789241565721

20. Smithson, P. et al. 2015. "Impact of malaria control on mortality and anemia among Tanzanian children less than five years of age 1999-2010," PLOS ONE 10(11): e0141112. doi: 10.1371/ journal.pone.0141112

21. World Bank. 2018. Incidence of malaria (per 1,000 population at risk) [Internet]. Available at: https://data.worldbank.org/ indicator/SH.MLR.INCD.P3. Accessed August 22, 2020.

22. President's Malaria Initiative. 2018. "Tanzania." Available at: https://www.pmi.gov/docs/default-source/default-document-library/country-profiles/tanzania_profile.pdf?sfvrsn=20. Accessed August 22, 2020.

23. Ministry of Health, Community Development, Gender, Elderly and Children (MoHCDGEC) [Tanzania Mainland], Ministry of Health (MoH) [Zanzibar], National Bureau of Statistics (NBS), Office of the ChiefGovernment Statistician (OCGS), and ICF. 2017. Tanzania Malaria Indicator Survey 2017. Dar es Salaam, Tanzania, and Rockville, Maryland, USA: MoHCDGEC, MoH, NBS, OCGS, and ICF. Available at: https://dhsprogram.com/ pubs/pdf/MIS31/MIS31.pdf. Accessed August 22, 2020.

24. FHI 360. 2018. "Baseline evaluation of the USAID Tulonge Afya Project in Tanzania." https://assets. prb.org/rla/usaid-tulongeafya-revised-baseline-report.pdf. Accessed August 22, 2020.

25. Korenromp, K., M. Hamilton, and R. Sanders. 2019. “KPI 4 assessment of the national malaria program of mainland Tanzania" [Internet]. Spectrum available at: https://avenirhealth.org/software-spectrum.php. 
26. FHI 360. 2018. "Tulonge Afya Annual Performance Report: October 2017-September 2018."

27. FHI 360. 2019. "Tulonge Afya Annual Performance Report: October 2018-September 2019."

28. FHI 360. 2020. "Tulonge Afya Quarterly Performance Report: October 2019-December 2019."

29. President's Malaria Initiative. 2019. "Tanzania Malaria Operational Plan FY 2019."

30. President's Malaria Initiative. 2020. "Tanzania Malaria Operational Plan FY 2020."

31. Tanzania Communication and Development Center. 2020. "Kiungo cha Mabadiliko ya Kutokomeza Ugonjwa wa Malaria Project." Progress Report January-December 2019.

32. Tanzania Communication and Development Center. 2020. "Kiungo cha Mabadiliko ya Kutokomeza Ugonjwa wa Malaria Project." Progress Report January-June 2020.

33. President's Malaria Initiative. 2018. "Côte d'Ivoire." Available at: https://www.pmi.gov/docs/default-source/default-document-library/country-profiles/cote_divoire_profile.pdf. Accessed August 22, 2020.

34. Korenromp, E.L., M. Hamilton, D. Weiss, and N. Oliphant. 2020. "Modélisation d'interventions, d'impact sur la santé et de la rentabilité, en vue de la planification stratégique du Programme Nationale de Lutte contre le Paludisme (PNLP) en Côte d'Ivoire.» Spectrum available at: https://avenirhealth. org/software-spectrum. php.

35. Breakthrough ACTION. 2019. "Survey on the determinants of malaria-related behaviors in Côte d'Ivoire." Baltimore, MD: Johns Hopkins Center for Communication Programs.

36. President's Malaria Initiative. 2019. Côte d'Ivoire Malaria Operational Plan FY 2018 and FY 2019.
37. President's Malaria Initiative. 2020. Côte d'Ivoire Malaria Operational Plan FY 2020.

38. Breakthrough ACTION. 2020. "Ivory Coast Presidential Malaria Initiative Quarterly Report April 1 to June 20, 2020."

39. Gunda, R. and M. J. Chimbari. 2017. "Cost-effectiveness analysis of malaria interventions using disability-adjusted life years: A systematic review," Cost Effectiveness and Resource Allocation 15: 10. doi: 10.1186/s12962-017-0072-9

40. The Health Communication Capacity Collaborative (HC3). 2017. "Malaria SBCC evidence literature review." Baltimore, MD: Johns Hopkins Center for Communication Programs.

41. Perkins, J. M. et al. 2019. "Social norms, misperceptions, and mosquito net use: A population-based, cross-sectional study in rural Uganda," Malaria Journal 18: 189. doi: 10.1186/ s12936-019-2798-7

42. Mchwampaka, W. M. et al. 2019. "Factors affecting uptake of $>3$ doses of sulfadoxine-pyrimathamine for malaria prevention in pregnancy in selected health facilities, Arusha region, Tanzania," BMC Pregnancy and Childbirth 19(1): 440. doi: 10.1186/s12884-019-2592-0.

43. Muhumuza, E. et al. 2016. "Factors associated with use of malaria control interventions by pregnant women in Buwunga subcounty, Bugiri District," Malaria Journal 15: 342. doi: 10.1186/s12936-016-1407-2

44. Breakthrough RESEARCH. 2019. "Developing research and learning agendas to strengthen social and behavior change programming." Washington, DC: Population Council. Available at: https://breakthroughactionandresearch.org/wp-content/ uploads/2019/02/RLA-Overview.pdf. 


\section{Appendix A: Additional methodological details}

\section{Effectiveness literature synthesis}

Based on the SBC categories and the outcomes (both behavioral and intermediate), each observation could be classified into a "bucket" examining the same intervention and outcome. To avoid an overreliance on one or two studies, there needed to be at least three studies that examined the impact for a bucket to be included in the analysis. Two studies could be deemed sufficient, however, if at least one of the studies was a randomized controlled study or rigorous quasi-experimental analysis.

To find a common metric within the buckets, an OR was sought for each outcome observation. For many observations, the OR (or adjusted ORs) were reported and already extracted. In other instances, the ORs needed to be calculated from extracted data, most commonly using pre/post percentage data. Logistic regression coefficients were exponentiated; however, linear regression coefficients were not utilized since they could not be converted to ORs.

Within each bucket, a study was limited to one observation to represent the strength of the association between the intervention and outcome. If a study had multiple observations within a bucket from the same study, either the ORs were averaged or the most representative observation was chosen. For example, if the study reported findings from multiple sites, the researcher averaged the ORs across sites to get the average effect size. In contrast, if multiple outcomes from the same study in the same bucket were different indicators and one was clearly more representative of the intermediate outcome, the researcher selected that outcome to represent the study. If the appropriate approach was not clear, the researcher consulted the broader research team for consensus on the best approach.

Each observation within a bucket was weighted based on the "strength of evidence" scores generated by Breakthrough ACTION for the malaria SBC studies. ORs were extracted regardless of whether they were statistically significant at $p<0.05$; however, statistical significance was a factor in the weighted score.
Breakthrough ACTION's scoring system was developed by a group of researchers at the Johns Hopkins University Center for Communications Programs and scored the studies between 0 and 15 based on study design, sampling, analysis, and reporting. Studies scoring a weight of 0 to 7 were weighted as 1 , followed by those scoring 8 to 11 (weight of 2), and studies scoring 12 or more (weight of 3). New "strength of evidence" scores were generated for newer studies that had not been previously scored, using the criteria specified by Breakthrough ACTION. After weighting, the median OR value was taken for each bucket to represent the relationship between the SBC intervention and the outcome.

For the literature examining the second link between intermediate determinants and behavioral outcomes, a similar process was used with each finding classified as an observation into the intermediate determinant/ behavioral outcome buckets. As with linking SBC to other outcomes, when studies had multiple observations in a bucket, they were either combined or the most relevant observation was selected. Most studies examining the relationship between intermediate determinants and malaria behaviors were cross-sectional logistic regression analysis. Because "strength of evidence" scores were not available for most LINK 2 studies, outcomes were weighted as a 1 for a crude OR and a 2 for an adjusted OR that controlled for demographic and other variables.

\section{Modeling impact pathways}

Figures A1 through A4 detail the impact pathways from SBC interventions to malaria behaviors, through intermediate determinants. For ITN use, the first pathways distinction is that SBC interventions can influence ITN use through two mechanisms: (1) through increasing adequate access to ITNs and (2) through increasing use among those with adequate access, as defined as one net for every two people in the household (Figure A1).

Figures $A 2$ and $A 3$ illustrate the impact pathways for each stream. Figure $\mathbf{A} \mathbf{2}$ shows SBC interventions linking with the dark blue lines to the intermediate determinants in 
FIGURE A1 SBC LINKAGES TO ITN USE

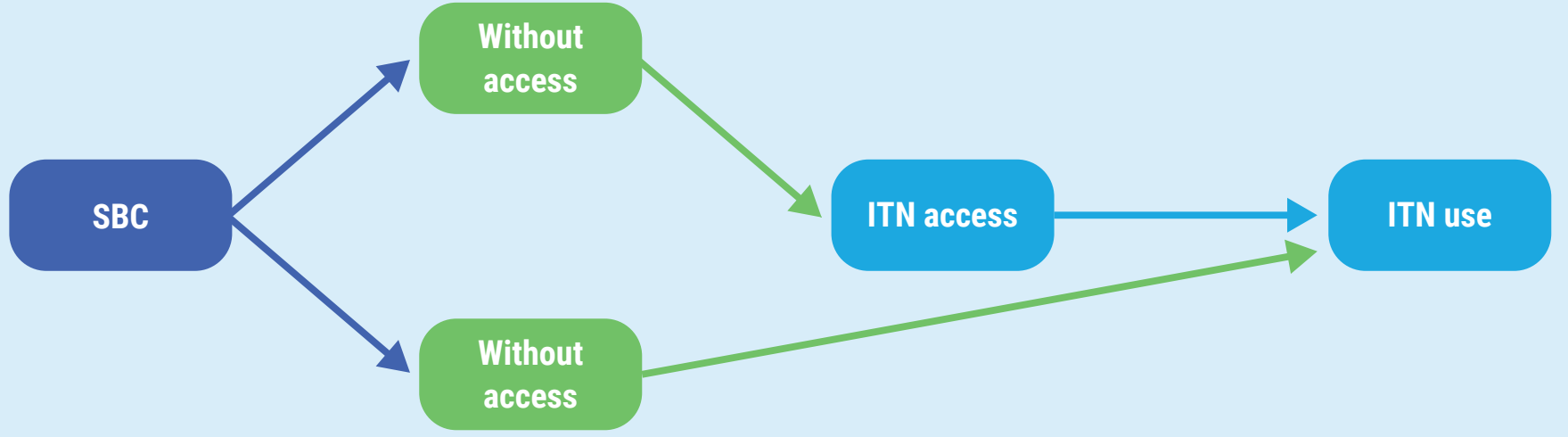

Figure A1 shows how SBC interventions can influence those with and without access to ITNs. Access to ITNs is defined as the percentage of the population that could sleep under an ITN if each ITN in a household were used by two people.

the orange boxes (LINK 1 in Table 2), the intermediate determinants linking to ITN access in bright blue (LINK 2), the direct link of SBC interventions to ITN access (LINK 3), and the final link from access to ITN use (green).

Figure $\mathbf{A} \mathbf{3}$ focuses on the connections to ITN use via the direct links and intermediate determinants, including an additional determinant of communication. The width of the lines represents the strength of the relationship between the two variables, based on the median ORs on a log scale. In addition to the direct links from SBC to

FIGURE A2 SBC PATHWAYS FOR ITN USE AMONG THOSE WITHOUT ACCESS

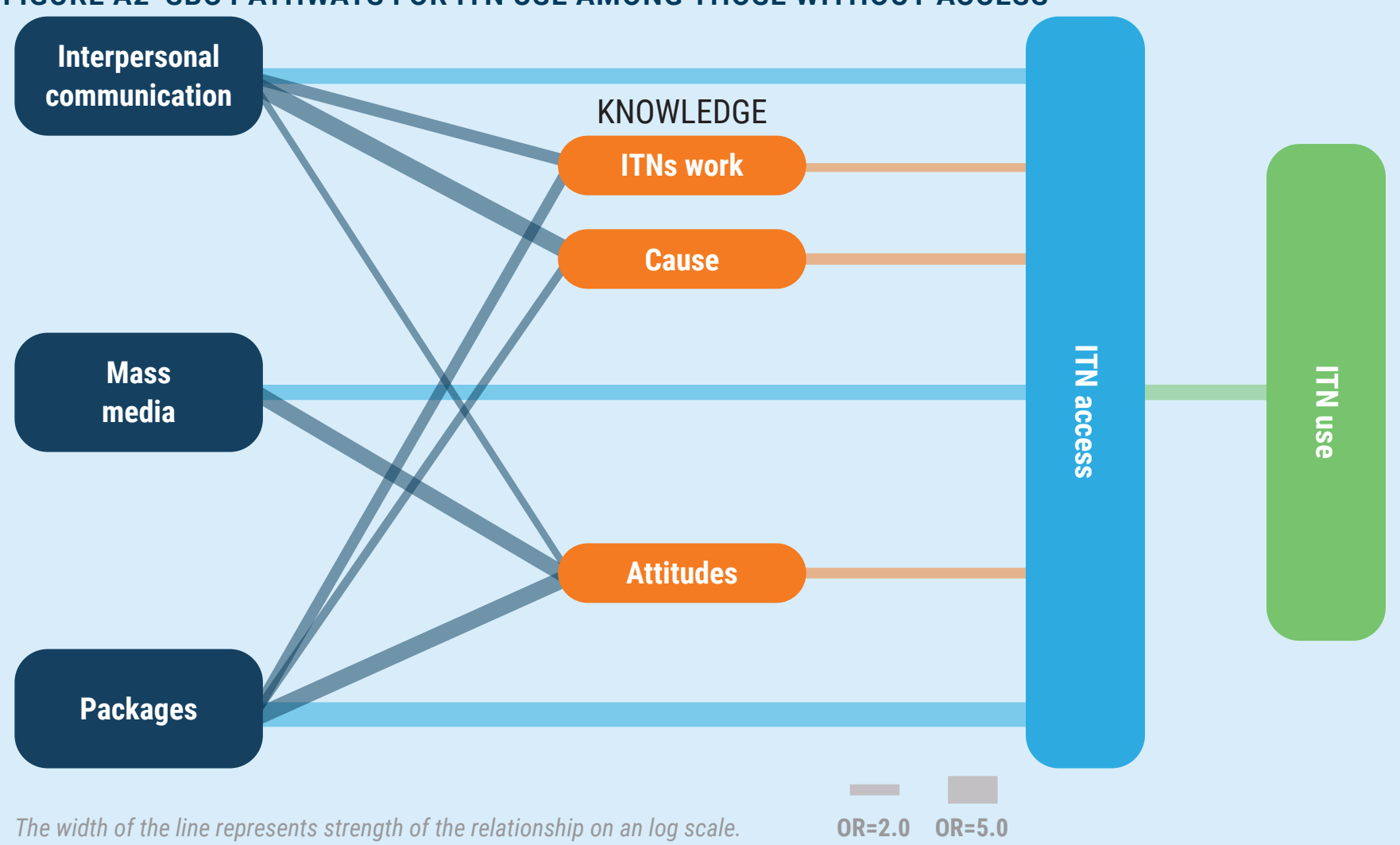

Figure A2 shows the pathways from SBC interventions to ITN use through the intermediate determinants of knowledge and positive attitudes, which improve ITN access and subsequently ITN use. Note that the knowledge and attitude determinants are those with sufficient literature to include and do not necessarily represent the most important or impactful intermediate determinants. 
FIGURE A3 SBC PATHWAYS FOR ITN USE AMONG THOSE WITH ACCESS

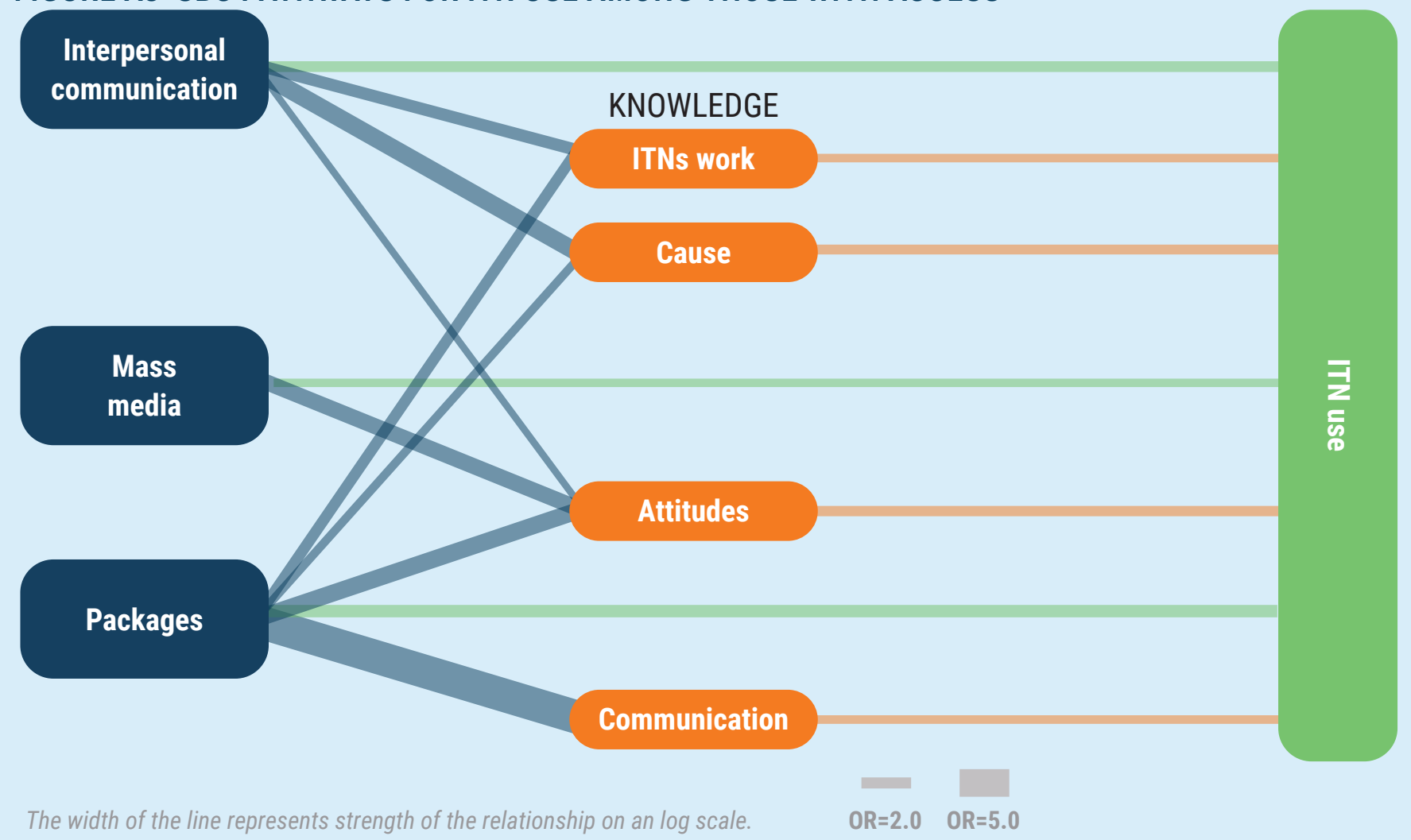

Figure A3 shows the pathways from SBC interventions to ITN use through the intermediate determinants of knowledge, positive attitudes, and communication about malaria, which improve ITN use among those with adequate ITN access. Note that the knowledge and attitude determinants are those with sufficient literature to include and do not necessarily represent the most important or impactful intermediate determinants.

ITN use, IPC and SBC packages were linked through both knowledge and attitude intermediate determinants, while mass media was only linked through attitudes because there was insufficient evidence to link mass media to the knowledge intermediate determinants.

Figure A4 illustrates the pathways to impact for case management of uncomplicated malaria. Only knowledge intermediate determinants were included due to a lack of evidence for incorporating other intermediate determinants like attitudes and communication. IPC and SBC packages were linked via the knowledge intermediate determinants, while mass media and SMS reminders only had sufficient evidence for a direct link.

\section{Unit cost analysis}

The primary objective of the SBC cost analysis was to identify and standardize SBC unit costs that can be used in conjunction with the country-specific scale-up scenarios to generate estimated costs and cost-effectiveness findings. This required the following research steps: (1) identify SBC costing studies, (2) extract cost data, and (3) analyze extracted data to calculate median unit costs for different intervention types.

1. Identify SBC cost studies

An earlier review and synthesis of the SBC for cost literature was conducted. ${ }^{7}$ The prior review did not restrict cost data to family planning SBC but also captured SBC costs for other health areas, including malaria. Building on the prior search synthesis, additional cost data were sought specific to malaria SBC interventions. A supplemental search in PubMed was conducted in October 2019 using the following search terms:

(/((Cost[Title/Abstract] OR Price[Title/Abstract] OR "Health economic"[Title/Abstract] OR Dollar[Title/ Abstract] OR USD[Title/Abstract] OR \$[Title/Abstract] OR $€[$ Title/Abstract] OR $£$ [Title/Abstract])) AND (SBC[Title] OR IPC[Title] OR “Interpersonal counseling"[Title] OR 
FIGURE A4 SBC PATHWAYS FOR CASE MANAGEMENT OF UNCOMPLICATED MALARIA

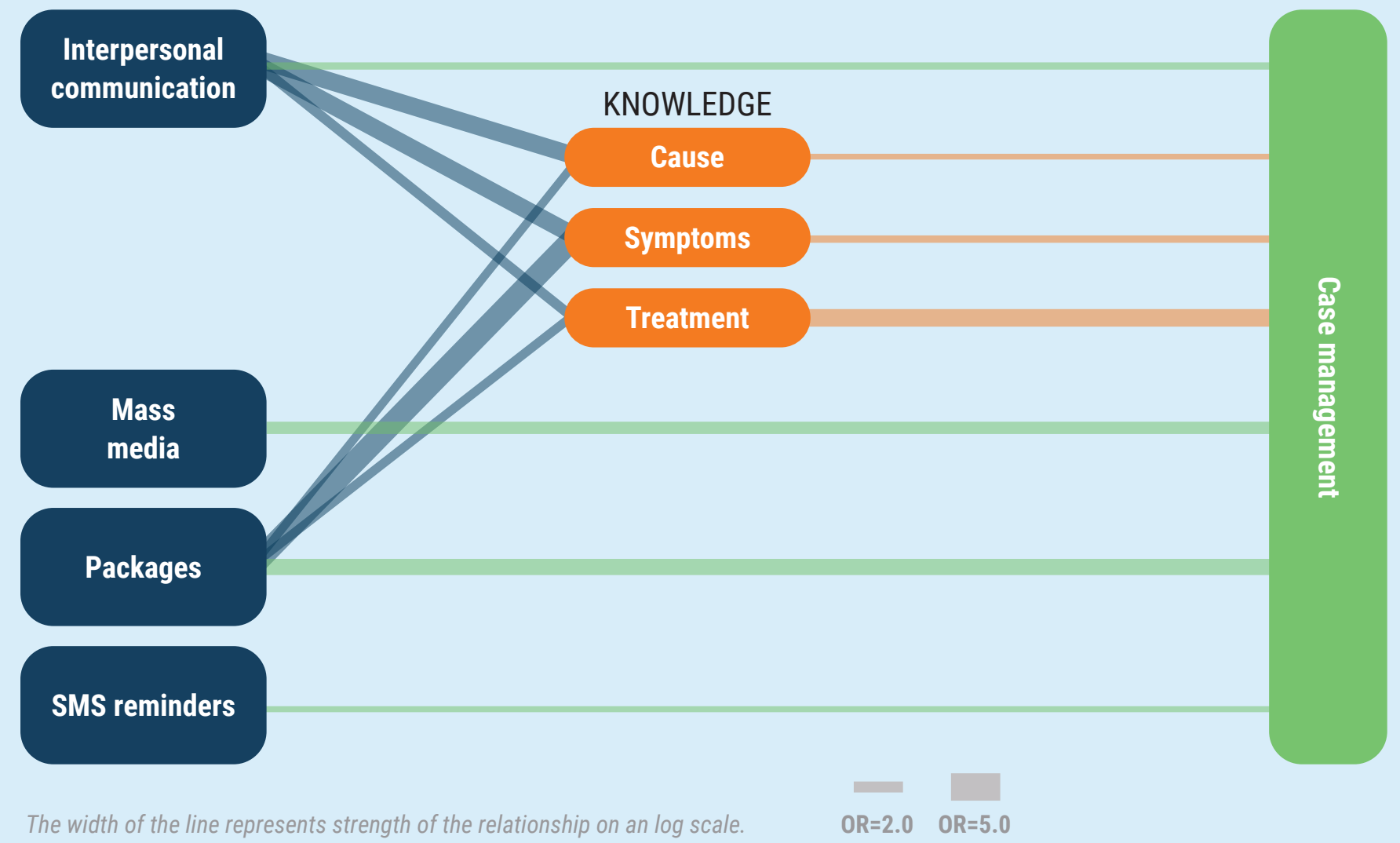

Figure A4 shows the pathways from SBC interventions to appropriate case management of uncomplicated malaria by improving care seeking and treatment adherence through the intermediate determinants of knowledge. Note that the knowledge determinants are those with sufficient literature to include and do not necessarily represent the most important or impactful intermediate determinants.

"Intrapersonal counseling"[Title] OR "Face-to-face"[Title] OR "Social marketing"[Title] OR "Social mobilization"[Title] OR "Social change"[Title] OR "Socio-behavioral”[Title] OR Socio-behavioural[Title] OR "Change behavior"[Title] OR "Change behaviour"[Title] OR "Planned behavior"[Title] OR "Planned behaviour"[Title] OR "Behavior change"[Title] OR "Behaviour change"[Title] OR "Behavioral change"[Title] OR "Behavioural change"[Title] OR "Behavioral economic"[Title] OR "Behavioural economic"[Title] OR Attitude[Title] OR Norm[Title] OR Tradition[Title] OR Traditional[Title] OR “Demand creation"[Title] OR “Demand generation"[Title] OR "Demand generating"[Title] OR "Generate demand"[Title] OR “Demand-side"[Title] OR "Demand side"[Title] OR mHealth[Title] OR "M-health"[Title] OR Adhere[Title] OR Communication[Title] OR Advocacy[Title] OR Outreach[Title] OR Mobile[Title] OR Campaign[Title] OR Media[Title] OR Advertise[Title] OR Advertisement[Title] OR Entertain[Title] OR Edutainment[Title] OR

Drama[Title] OR Digital[Title] OR SMS[Title] OR
"Text message"[Title] OR "Text-message"[Title" OR Phone[Title] OR Peer[Title] OR "Behavioral design"[Title] OR "Behavioural design"[Title] OR "Design behave"[Title] OR "Human-centered design"[Title] OR "Human centered design"[Title] OR Radio[Title] OR Television[Title] OR TV[Title])) AND (Malaria[Title] OR Provider[Title] OR PBC[Title] OR "IRS"[Title] OR Spray[Title] OR “ITN"[Title] OR LLIN[Title] OR “Net"[Title] OR "ACT"[Title] OR Artemisinin[Title] OR "Seasonal malaria chemoprevention"[Title] OR "Seasonal malaria chemoprophylaxis"[Title] OR "SMC"[Title] OR "IPTp"[Title] OR "IPTp-SP"[Title] OR "IPTi"[Title] OR “IPTc"[Title] OR Intermittent[Title] OR Fever[Title] OR Microscopy[Title] OR "Rapid diagnostic test"[Title]))

These search terms yielded 825 abstracts, of which 51 met inclusion criteria for a full-text review. Of these, 22 new malaria-specific studies were selected for extraction. Put together with the original search, Figure A5 (next page) shows the PRISMA diagram for all included SBC cost studies. 
FIGURE A5 SBC COST LITERATURE SEARCH RESULTS DIAGRAM

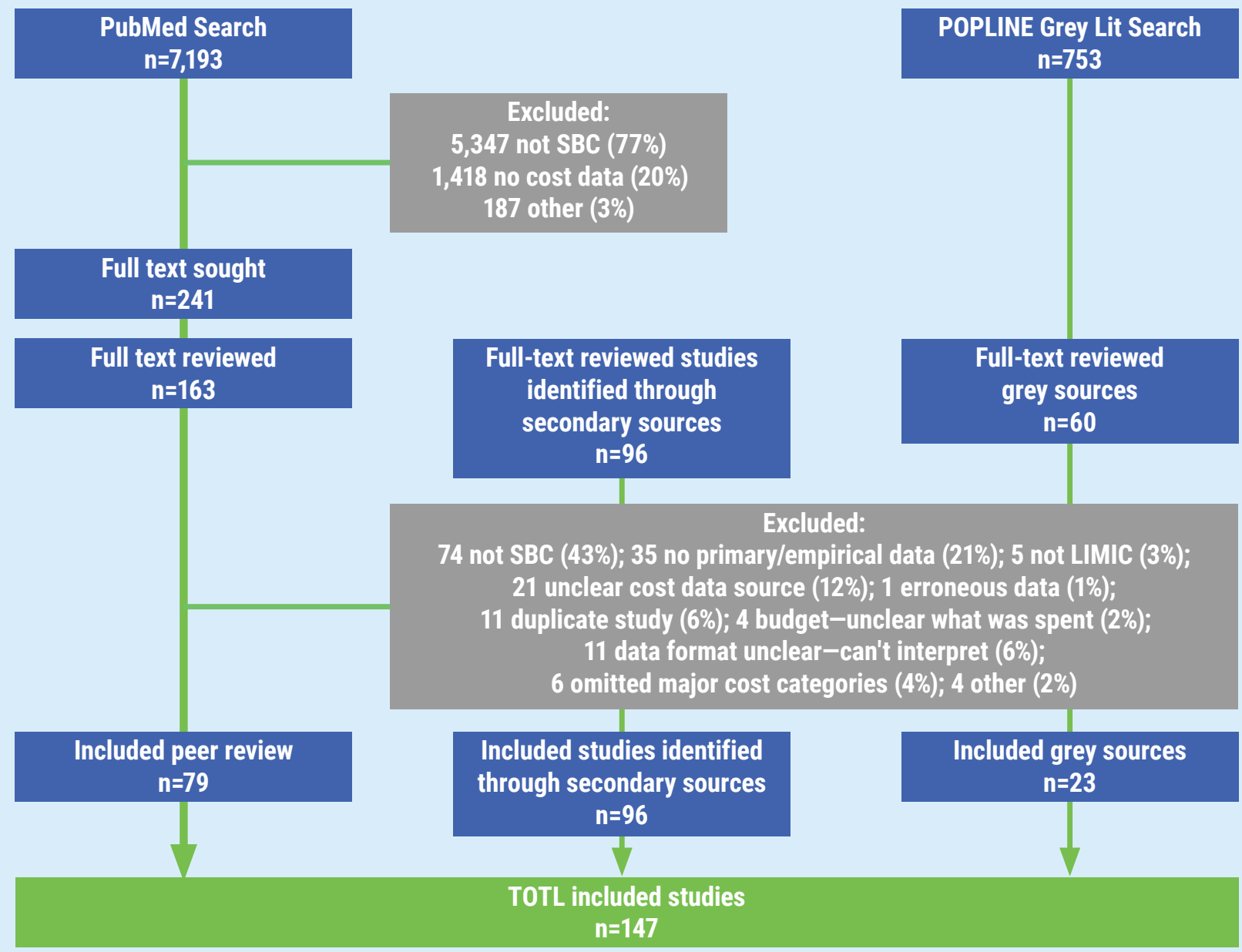

\section{Extract cost data}

The Microsoft Excel cost data extraction template used previously for the family planning business case was adapted to accommodate some malaria-specific cost considerations, such as adding an option for cost per household participated to the list of units of measurement. Table A1 details the various data elements extracted for each study and cost observation.

Cost data extraction occurred in February 2020. In total, the resulting SBC cost repository included 147 studies and 867 cost estimates, of which 134 were malaria-specific and 67 were from integrated programs that often included a malaria component. Of the 867 cost estimates, 355 were unit costs (as compared to total program cost or cost-effectiveness estimates), and 120 of those unit cost estimates met the standardization filter criteria to be included in the cost analysis.
3. Analyze extracted data for median unit costs

Preparing the extracted cost data for analysis required several steps, including:

a. Where necessary, dividing the author-provided total cost (numerator) by the quantity of units measured (denominator) to create a unit cost.

b. Where necessary, multiplying the number of people targeted by the percentage exposed/participated to get a number exposed/participated that could be used as a denominator for calculating a unit cost.

c. Where necessary, generating a time period from the dates reported for the beginning and end of the intervention when the time period of the costs was not given.

d. In cases where the study author did not give a year for the reported cost data, using a formula that took the publication date and subtracted one year to create an estimated year of the cost data (that could be used for inflation purposes). 
TABLE A1 DATA EXTRACTION FORM COMPONENTS

\begin{tabular}{|c|c|}
\hline INFORMATION TYPE & SPECIFIC FIELDS \\
\hline Study identification & Study ID, lead author, all authors, year of publication, title, journal, URL \\
\hline SBC intervention description & Health area, main intervention type, intervention details, data collection years \\
\hline Means of service delivery; geography & Platform¹, ownership², geographic scope ${ }^{3}$, country, region, urban/rural \\
\hline Population and dissemination & Population served, number targeted, number exposed/participated \\
\hline Cost type and parameters & $\begin{array}{l}\text { Cost category/type, economic/financial costs }{ }^{4} \text {, cost perspective }{ }^{5} \text {, unit of measurement, duration of } \\
\text { measurement, intervention phase, scale }\end{array}$ \\
\hline Cost details & $\begin{array}{l}\text { Cost per output/outcome, currency, currency year, currency conversion, cost component amounts } \\
\text { (personnel, commodities, recurrent, capital, above-site, and other), cost inputs, client costs, rev- } \\
\text { enues, scale, sensitivity analysis, further cost methodology details, cost calculation explanation, } \\
\text { additional notes }\end{array}$ \\
\hline
\end{tabular}

'Platform is the channel of service delivery, such as through fixed facilities like clinics or through outreach modalities like mobile vans.

${ }^{2}$ Ownership refers to the type of organizations funding and/or implementing the intervention, whether public/government, private, local NGO, international NGO, or a mix of these.

${ }^{3}$ Geographic scope means whether the intervention was implemented nationally, regionally, or at the local level of a city or group of villages.

"Economic costs reflect the full value of all resources utilized in producing a good or service, inclusive of "opportunity costs" that represent the value of the forgone opportunity to devote unpaid resources (such as volunteer time and donated goods) to another purpose. Financial costs reflect financial outlays for goods and services needed to carry out a public health or medical intervention, similar to expenditures. However, in contrast to expenditure data, financial costs depreciate capital expenditures over time.

${ }^{5}$ The perspective can typically be provider, societal, or client. According to the SBC Costing Guidelines, 43 the provider perspective includes costs by the service provider to produce the activity, service, or intervention at the point of care, while the societal perspective includes all costs, regardless of payor. The client perspective can include costs not typically included in other perspectives, such as travel expenses and lost wages due to the time spent obtaining care. Due to data limitations, the perspective in the extraction template was broken into provider, provider including revenues, client, above-site only costs, health system (provider + above-site), and societal (provider + client).

e. Standardizing all costs to the 2019 USD (to align with the year/denomination used in the Unit Cost Study Repository by first converting local currency to USD for the reported (or estimated) year of cost data using market exchange rates, then inflating using the US GDP price deflator

f. Dividing the costs reported as per couple by 2 to obtain a per person cost.

g. Averaging costs (and denominators) reported in the same study for multiple sites or multiple years that had the same country, service delivery platform, target population, ownership, urbanicity, and intervention phase to avoid overrepresentation of data from single studies.

Once the entire cost data set was extracted, standardized, and cleaned, analysis was conducted to summarize unit cost findings for a subset of results. To be included in the analysis, the unit costs were filtered to allow only for inclusion of those unit costs with the following criteria:

a. The cost type was listed as a unit cost for an SBC intervention or an SBC component (excludes total cost and cost-effectiveness estimates and excludes non-SBC intervention cost estimates and mixed intervention cost estimates). b. Costing was done from a provider costing perspective (excludes estimates that include revenue, above-site only costs, and studies from the health system and client perspectives).

c. The unit cost was from the intervention phase of implementation or overall implementation (excludes design, training, start-up, or scale-up only phases).

d. The unit cost included a unit of measurement of cost per person exposed, cost per person participated, or cost per person contacted appropriate to the intervention type.

e. The cost estimate was relevant to the SBC interventions listed in Table 1. We did not include extracted unit costs for social marketing in the analysis due to challenges in isolating provider costs, since factors affecting the reported cost estimates (e.g., subsidies, revenues) often could not be disaggregated.

f. The study data did not suffer from methodological issues incompatible with aggregated analysis (e.g., medical commodities costs could not be separated from the SBC costs, or the unit of measurement was not clear). 


\section{Appendix B: Literature synthesis references}

Acosta, A. et al. 2018. "Design, implementation, and evaluation of a school insecticide-treated net distribution program in Cross River State, Nigeria," Global Health: Science and Practice 6(2): 272-287. doi: 10.9745/GHSP-D-17-00350

Adjah, E. S. O. and A. G. Panayiotou. 2014. "Impact of malaria-related messages on insecticide-treated net (ITN) use for malaria prevention in Ghana," Malaria Journal 13(1): 123. doi: 10.1186/1475-2875-13-123

Ahmed, S. M., M. S. Hossain, and M. Kabir. 2014. "Conventional or interpersonal communication: Which works best in disseminating malaria information in an endemic rural Bangladeshi community?," PLOS ONE 9(3): e90711.

Ajayi, I. O. et al. 2008. "Assessment of a treatment guideline to improve home management of malaria in children in rural southwest Nigeria," Malaria Journal 7: 24. doi: 10.1186/1475-2875-7-24

Akewongo, P. et al. 2011. "Feasibility and acceptability of ACT for the community case management of malaria in urban settings in five African sites," Malaria Journal 10: 240. doi: 10.1186/1475-2875-10-240

Amoran, O. E., K. O. Fatugase, O. M. Fatugase, and K. O. Alausa. 2012. "Impact of health education intervention on malaria prevention practices among nursing mothers in rural communities in Nigeria," BMC Research Notes 5: 444. doi: 10.1186/1756-0500-5-444

Anderson, F. J. 2014. "Evaluation: Maternal and Child Health Transformation Project in Warrap State South Sudan." Washington, DC: World Vision.

Ankomah, A. et al. 2014. "The effect of mass media campaign on the use of insecticide-treated bed nets among pregnant women in Nigeria," Malaria Research and Treatment 2014: 694863. doi: $10.1155 / 2014 / 694863$

Awantang, G. et al. 2018. "Correlates of social behavior change communication on care-seeking behaviors for children with fever: an analysis of malaria household survey data from Liberia," Malaria Journal 17(1): 105. doi: 10.1186/s12936-018-2249-x.

Awuah, R. B. et al. 2018. "Factors associated with treatment-seeking for malaria in urban poor communities in Accra, Ghana," Malaria Journal 17: 168. doi: 10.1186/s12936-018-2311-8

Babalola, S. et al. 2018. "Factors associated with caregivers' consistency of use of bed nets in Nigeria: A multilevel multinomial analysis of survey data," Malaria Journal 17: 280. doi: 10.1186/ s12936-018-2427-x

Balami, A. D. et al. 2019. "Effects of a health educational intervention on malaria knowledge, motivation, and behavioural skills: A randomized control trial," Malaria Journal 18: 41. doi: 10.1186/ s12936-019-2676-3
Baume, C. A., R. Reithinger, and S. Woldehanna. 2009. "Factors associated with use and non-use of mosquito nets owned in Oromia and Amhara Regional States, Ethiopia," Malaria Journal 8: 264. doi: 10.1186/1475-2875-8-264

Bennett, A. et al. 2012. "Household possession and use of insecticide-treated mosquito nets in Sierra Leone 6 months after a national mass-distribution campaign," PLOS ONE 7(5): e37927. doi: 10.1371/journal.pone.0037927

Berkessa, T., D. Oljira, and B. Tesfa. 2016. "Insecticide-treated nets use and its determinants among settlers of Southwest Ethiopia," BMC Public Health 16: 106. doi: 10.1186/s12889-016-2768-8

Biadgilign, S., A. Reda, and H. Kedir. 2012. "Determinants of ownership and utilization of insecticide-treated bed nets for malaria control in Eastern Ethiopia," Journal of Tropical Medicine 2012: 235015. doi: 10.1155/2012/235015.

Bonner, K. et al. 2011. "Design, implementation and evaluation of a national campaign to distribute nine million free LLINs to children under five years of age in Tanzania," Malaria Journal 10: 73. doi: 10.1186/1475-2875-10-73.

Boulay, M., M. Lynch, and H. Koenker. 2014. "Comparing two approaches for estimating the causal effect of behaviour-change communication messages promoting insecticide-treated bed nets: an analysis of the 2010 Zambia malaria indicator survey," Malaria Journal 13: 342. doi: 10.1186/1475-2875-13-342

Bowen, H. L. 2013. "Impact of a mass media campaign on bed net use in Cameroon," Malaria Journal 12: 36. doi: 10.1186/1475-2875-12-36

Bradbury, K. and A. Edward. 2005. "Community-based solutions for effective malaria control: lessons from Mozambique." Washington, DC: Core Group.

Bruxvoort, K. et al. 2014. "Cluster randomized trial of text message reminders to retail staff in Tanzanian drug shops dispensing artemether-lumefantrine: Effect on dispenser knowledge and patient adherence," American Journal of Tropical Medicine and Hygiene 91(4): 844-853. doi: 10.4269/ajtmh.14-0126

Canavati, S. E. et al. 2016. "Evaluation of intensified behaviour change communication strategies in an artemisinin resistance setting," Malaria Journal 15: 249. doi: 10.1186/s12936-016-1276-8

Capps, J. 2013. "Final evaluation for Nehnwaa Child Survival Project: Census-based impact-oriented methodology for community-based primary health care in Nimba County, Liberia." Raleigh, NC: Curamericas Global.

C-Change. 2013. "C-Change Ethiopia final report." Washington DC: FHI 360. 
Chourasia, M. K., V. J. Abraham, and J. John. 2014. "Household training vs. mass campaigns: a better method of health communication for preventing malaria," Tropical Doctor 44(4): 196-200. doi: 10.1177/0049475514545201

Cohen, J. and I. Saran. 2018. "The impact of packaging and messaging on adherence to malaria treatment: Evidence from a randomized controlled trial in Uganda," Journal of Development Economics 134: 68-95. doi: 10.1016/j.jdeveco.2018.04.008

Cropley, C. 2004. "The effect of health education interventions on child malaria treatment-seeking practices among mothers in rural refugee villages in Belize, Central America," Health Promotion International 19(4): 445-452. doi: 10.1093/heapro/dah406

Das, A. et al. 2015. "Strengthening malaria service delivery through supportive supervision and community mobilization in an endemic Indian setting: An evaluation of nested delivery models," Malaria Journal 13: 482. doi: 10.1186/1475-2875-13-482

De La Cruz, N. et al. 2009. "Microfinance against malaria: impact of Freedom from Hunger's malaria education when delivered by rural banks in Ghana," Transactions of the Royal Society of Tropical Medicine \& Hygiene 103(12): 1229-1236.

Deressa, W. et al. 2014. "Individual and household factors associated with use of insecticide-treated nets in southern Ethiopia," Transactions of the Royal Society of Tropical Medicine \& Hygiene 108: 616-624. doi: 10.1093/trstmh/tru129

Deressa, W. 2017. "Individual and household factors associated with ownership of long-lasting insecticidal nets and malaria infection in south-central Ethiopia: A case-control study," Malaria Journal 16: 402. doi: 10.1186/s12936-017-2048-9

Deribew, A. et al. 2012. "The effect of household heads training on long-lasting insecticide-treated bednets utilization: a cluster randomized controlled trial in Ethiopia," Malaria Journal 11(1): 99. doi: 10.1186/1475-2875-11-99

Desrochers, R. E. et al. 2014. "Effectiveness of post-campaign, door-to-door, hang-up, and communication interventions to increase long-lasting, insecticidal bed net utilization in Togo (2011-2012): A cluster randomized, control trial," Malaria Journal 13: 260. doi: 10.1186/1475-2875-13-260

Do, M. et al. 2018. "Associations between malaria-related ideational factors and care-seeking behavior for fever among children under five in Mali, Nigeria, and Madagascar," PLOS ONE 13(1): e0191079. doi: 10.1371/journal.pone.0191079

Elmosaad, Y. F. et al. 2016. “Communication for behavioural impact in enhancing utilization of insecticide-treated bed nets among mothers of under-five children in rural North Sudan: An experimental study," Malaria Journal 15: 509. doi: 10.1186/ s12936-016-1551-8

Escribando-Ferrer, B. et al. 2017. "Effectiveness of two community-based strategies on disease knowledge and health behaviour regarding malaria, diarrhoea and pneumonia in Ghana," BMC Public Health 17: 948. doi: 10.1186/s12889-017-4964-6

Finlay, A. M. et al. 2017. "Free mass distribution of long-lasting insecticidal nets lead to high levels of LLIN access and use in Madagascar, 2010: A cross-sectional observational study," PLoS ONE 12(8): e0183936.
Fuge, T. G., S. Ayonto, and F. L. Gurmamo. 2015. "Assessment of knowledge, attitude and practice about malaria and ITNs utilization among pregnant women in Shashogo District, Southern Ethiopia," Malaria Journal 14: 235.

Geonuppakul, M., P. Butraporn, S. Leemingsawat, and O. Pacheun. 2007. "An empowerment program to enhance women's ability to prevent and control malaria in the community, Chiang Mai Province, Thailand," The Southeast Asian Journal of Tropical Medicine and Public Health 38(3): 546-559.

Grabowski, M. et al. 2005. "Distributing insecticide-treated bednets during measles vaccination: a low-cost means of achieving high and equitable coverage," Bulletin of the World Health Organization 83(3): 195-201.

He, C. H. et al. 2014. "Eliminating Plasmodium falciparum in Hainan, China: A study on the use of behavioural change communication intervention to promote malaria prevention in mountain worker populations," Malaria Journal 13: 273. doi: 10.1186/1475-2875-13-273

Helinski, M. H. 2015. "Impact of a behaviour change communication programme on net durability in eastern Uganda," Malaria Journal 14: 366. doi: 10.1186/s12936-015-0899-5

Hwang, J. et al. 2019. "Knowledge of malaria and its association with malaria-related behaviors - results from the Malaria Indicator Survey, Ethiopia, 2007," PLOS ONE 5(7): e11692. doi: 10.1371/journal.pone.0011692

Ingabire, C. M. et al. 2016. "Determinants of prompt and adequate care among presumed malaria cases in a community in eastern Rwanda: A cross sectional study," Malaria Journal 16: 227. doi: 10.1186/s12936-016-1285-7

Ingabire, C. M. et al. 2016. "Using an intervention mapping approach for planning, implementing and assessing a community-led project towards malaria elimination in the Eastern Province of Rwanda," Malaria Journal 15: 594. doi: 10.1186/ s12936-016-1645-3

Israel, O. K. et al. 2018. “Caregivers' knowledge and utilization of long-lasting insecticidal nets among under-five children in Osun State, Southwest, Nigeria," Malaria Journal 17: 231. doi: 10.1186/ s12936-018-2383-5

Johnson, A. D. et al. 2018. "Proactive community case management and child survival in periurban Mali," BMJ Global Health 3: e000634.

Kanyagarara, M. et al. 2018. "Malaria knowledge and bed net use in three transmission settings in southern Africa," Malaria Journal 17: 41. doi: 10.1186/s12936-018-2178-8

Kaufman, M. et al. 2014. "Wazazi Nipendeni (Love me, parents)! Impact of an Integrated National Safe Motherhood Campaign in Tanzania." Presentation at the 142nd American Public Health Association (APHA) Annual Meeting, New Orleans, LA, 15-19 November.

Keating, J. et al. 2012. "A quasi-experimental evaluation of an interpersonal communication intervention to increase insecticide-treated net use among children in Zambia," Malaria Journal 11: 313. doi: 10.1186/1475-2875-11-313 
Khadka, A. et al. 2018. "Malaria control across borders: quasi-experimental evidence from the Trans-Kunene malaria initiative (TKMI)," Malaria Journal 17: 224. doi: 10.1186/s12936-018-2368-4

Kilian, A. et al. 2015. "The effect of single or repeated home visits on the hanging and use of insecticide-treated mosquito nets following a mass distribution campaign-a cluster randomized, controlled trial," PLOS ONE 10(3): e0119078. doi: 10.1371/journal. pone.0119078

Kilian, A. et al. 2016. "The impact of behaviour change communication on the use of insecticide-treated nets: a secondary analysis of ten post-campaign surveys from Nigeria," Malaria Journal 15: 422. doi: 10.1186/s12936-016-1463-7

Kilian, A. et al. 2017. "Evaluation of a continuous community-based ITN distribution pilot in Lainya County, South Sudan 2012-2013," Malaria Journal 16: 363. doi: 10.1186/s12936-017-2020-8

Koenker, H. et al. 2015. "Impact of a behaviour change intervention on long-lasting insecticidal net care and repair behaviour and net condition in Nasarawa State, Nigeria," Malaria Journal 14: 18. doi: 10.1186/s12936-014-0538-6

Kolaczinski, J. H. et al. 2010. "Costs and effects of two public sector delivery channels for long-lasting insecticidal nets in Uganda," Malaria Journal 9: 102. doi: 10.1186/1475-2875-9-102

Krezanoski, P. J. et al. 2014. "Household malaria knowledge and its association with bednet ownership in settings without large-scale distribution programs: Evidence from rural Madagascar," Journal of Global Health 4(1): 010401. doi: 10.7189/jogh.04.010401

Kroeger, A., R. Meyer, M. Mancheno, and M. Gonzalez. 1996. "Health education for community-based malaria control: an intervention study in Ecuador, Columbia, and Nicaragua," Tropical Medicine and International Health 1(6): 836-846. doi: 10.1111/ j.1365-3156.1996.tb00119.x

Langston, A. et al. 2014. "Plausible role for $\mathrm{CHW}$ peer support groups in increasing care-seeking in an integrated community case management project in Rwanda: a mixed methods evaluation," Global Health: Science and Practice 2(3):342-354. doi: 10.9745/ GHSP-D-14-00067

Littrell, M. et al. 2013. "Narrowing the treatment gap with equitable access: mid-term outcomes of a community case management program in Cameroon," Health Policy and Planning 28(7): 705-716. doi: 10.1093/heapol/czs110

Liu, H. et al. 2015. "Coverage, use and maintenance of bed nets and related influence factors in Kachin Special Region II, northeastern Myanmar," Malaria Journal 14: 212. doi: 10.1186/ s12936-015-0727-y

Liu, J. X. and S. Modrek. 2016. "Evaluation of SMS reminder messages for altering treatment adherence and health-seeking perceptions among malaria care-seekers in Nigeria," Health Policy and Planning 31(10): 1374-1383. doi: 10.1093/heapol/czw076

Lwin, M. M., M. Sudhinaraset, San A. Kyaw, and T. Aung. 2014. "Improving malaria knowledge and practices in rural Myanmar through a village health worker intervention: a cross-sectional study," Malaria Journal 13:5. doi: 10.1186/1475-2875-13-5
Macintyre, K. et al. 2006. "Rolling out insecticide treated nets in Eritrea: examining the determinants of possession and use in malarious zones during the rainy season," Tropical Medicine and International Health 11(6): 824-833. doi: 10.1111/j.1365-3156.2006.01637.x

Marsh, V. M. et al. 1996. "Evaluating the community education programme of an insecticide-treated bed net trial on the Kenyan coast," Health Policy and Planning 11(3): 280-291. doi: 10.1093/ heapol/11.3.280

Mohammed, A. et al. 2019. "Mobile phone short message service (SMS) as a malaria control tool: a quasi-experimental study," BMC Public Health 1193. doi: 10.1186/s12889-019-7336-6

Muhumuza, E. et al. 2016. "Factors associated with use of malaria control interventions by pregnant women in Buwunga subcounty, Bugiri District," Malaria Journal 15: 342. doi: 10.1186/ s12936-016-1407-2

Mukhopadhyay, D. K. et al. 2016. "Netting the malaria menace: Distribution and utilization of long-lasting insecticidal nets in a malaria endemic area in Bankura, West Bengal," Journal of Vector Borne Diseases 53: 23-29.

Ndyomugyenyi, R. and A. Turinde Kabali. 2010. "Communitydirected interventions for integrated delivery of a health package against major health problems in rural Uganda: perceptions on the strategy and its effectiveness," International Health 2(3): 197-205. doi: 10.1016/j.inhe.2010.07.009

Nganda, R. Y., C. Drakeley, H. Reyburn, and T. Marchant. 2004. "Knowledge of malaria influences the use of insecticide treatment nets but not intermittent presumptive treatment by pregnant women in Tanzania," Malaria Journal 3: 42. doi: 10.1186/1475-2875-3-42

Nsungwa-Sabiiti, J. et al. 2007. "Home-based management of fever and malaria treatment practices in Uganda," Transactions of the Royal Society of Tropical Medicine \& Hygiene 101(12): 1199-1207. doi: 10.1016/j.trstmh.2007.08.005

Ntuku, H. M. et al. 2017. "Long-lasting insecticidal net (LLIN) ownership, use and cost of implementation after a mass distribution campaign in Kasaï Occidental Province, Democratic Republic of Congo," Malaria Journal 16: 22. 10.1186/s12936-016-1671-1

Nuwaha, F. 2001. "Factors influencing the use of bed nets in Mbarara municipality of Uganda," American Journal of Tropical Medicine and Hygiene 65(6): 877-882. doi: 10.4269/ ajtmh.2001.65.877

Ouédraogo, L. T., I. Ouédraogo, A. Yaméogo, and V. Ouédraogo. 2013. "Determinants of long-lasting insecticidal net use in Burkina Faso after a mass distribution in the Diébougou health district," Revue d’Epidémiologie et Santé Publique 61(2): 121-7.

Ovadje, L. and J. Nriagu. 2016. "Multi-dimensional knowledge of malaria among Nigerian caregivers: implications for insecticide-treated net use by children," Malaria Journal 15: 516. doi: 10.1186/s12936-016-1557-2

Raifman, J. R. G., H. E. Lanthorn, S. Rokicki, and G. Fink G. 2014. "The impact of text message reminders on adherence to antimalarial treatment in northern Ghana: a randomized trial," PLOS ONE 9(10): e109032. doi: 10.1371/journal.pone.0109032 
Renggli, S. et al. 2013. "Design, implementation and evaluation of a national campaign to deliver 18 million free long-lasting insecticidal nets to uncovered sleeping spaces in Tanzania," Malaria Journal 12: 85. doi: 10.1186/1475-2875-12-85

Rhee, M. et al. 2005. "Use of insecticide-treated nets (ITNs) following a malaria education intervention in Piron, Mali: a control trial with systematic allocation of households," Malaria Journal 4: 35. doi: 10.1186/1475-2875-4-35

Rickard, D. et al. 2010. "Closing the gap between insecticidetreated net ownership and use for the prevention of malaria," Progress in Community Health Partnerships 5(2): 123-31. doi: 10.1353/cpr.2011.0018

Ricotta, E. E. et al. 2015. "The use of mediation analysis to assess the effects of a behaviour change communication strategy on bed net ideation and household universal coverage in Tanzania," Malaria Journal 14: 15. doi: 10.1186/s12936-014-0531-0

Russell, C. L. et al. 2015. "Determinants of bed net use in southeast Nigeria following mass distribution of LLINs: Implications for social behavior change interventions," PLOS ONE 10(10): e0139447.

Saha, K. B. et al. 2015. "Establishing communication mechanism for malaria prevention in Baiga tribal villages in Baiga Chak area of Dindori district, Madhya Pradesh," Indian Journal of Medical Research 141(5): 576-83. doi: 10.4103/0971-5916.159516

Sarasset, S. et al. 2018. "Effect of a mass radio campaign on family behaviours and child survival in Burkina Faso: a repeated cross-sectional, cluster-randomised trial," Lancet Global Health 6: e330-41. doi: 10.1016/S2214-109X(18)30004-4

Sign, M. P., K. B. Saha, S. K. Chand, and A. Anvikar. 2017. "Factors associated with treatment seeking for malaria in Madhya Pradesh, India," Tropical Medicine and International Health 22(11): 1377-1384. doi: 10.1111/tmi.12973

Talisuna, A. O. et al. 2017. "Efficacy of text-message reminders on paediatric malaria treatment adherence and their post-treatment return to health facilities in Kenya: a randomized controlled trial," Malaria Journal 16: 46. doi: 10.1186/s12936-017-1702-6

Tassew, A., R. Hopkins, and W. Deressa. 2017. "Factors influencing the ownership and utilization of long-lasting insecticidal nets for malaria prevention in Ethiopia," Malaria Journal 16: 262. doi: 10.1186/s12936-017-1907-8

Tobin-West, C. I. and E. N. Kanu EN. 2016. "Factors influencing the use of malaria prevention methods among women of reproductive age in peri-urban communities of Port Harcourt City, Nigeria," Nigerian Postgraduate Medical Journal 23: 6-11. doi: 10.4103/1117-1936.180114

USAID. 2014. Communications Support for Health (CSH) Programme. Zambia Communications Support for Health: Stop Malaria Champion Communities programme evaluation, CONTRACT NO: GHS-I-00-07-00004-00; Order No. GHS-I-05-0700004-00, USAID.
Wasunna, B. et al. 2015. "The impact of a community awareness strategy on caregiver treatment-seeking behaviour and use of artemether-lumefantrine for febrile children in rural Kenya," PLOS ONE 10(7): e0130305. doi: doi: 10.1371/journal.pone.0130305

Widmar, M. et al. 2009. "Determining and addressing obstacles to the effective use of long-lasting insecticide-impregnated nets in rural Tanzania," Malaria Journal 8: 315. doi: 10.1186/1475-2875-8-315

Winch, P. J. et al. 2003. "Increases in correct administration of chloroquine in the home and referral of sick children to health facilities through a community-based intervention in Bougouni District, Mali," Transactions of the Royal Society of Tropical Medicine \& Hygiene 97(5): 481-490. doi: 10.1016/ s0035-9203(03)80001-9

Wolkon, A. et al. 2010. "Rapid scale-up of long-lasting insecticide-treated bed nets through integration into the National Immunization Program during child health week in Togo, 2004," American Journal of Tropical Medicine and Hygiene 83(5): 1014-1019. doi: 10.4269/ajtmh.2010.09-0599

$X u, U$. et al. 2014. "Use of bed nets and factors that influence bed net use among Jinuo ethnic minority in southern China," PLOS ONE 9(7): e103780. doi: 10.1371/journal.pone.0103780

Yasuoka, J., T. W. Mangione, A. Spielman, and R. Levins. 2006. "Impact of education on knowledge, agricultural practices, and community actions for mosquito control and mosquito-borne disease prevention in rice ecosystems in Sri Lanka," American Journal of Tropical Medicine and Hygiene 74(6): 1034-1043. doi: 10.4269/ ajtmh.2006.74.1034

Yaya, S., O. A. Uthman, A. Amouzou, and G. Bishwajit. 2018. "Mass media exposure and its impact on malaria prevention behaviour among adult women in sub-Saharan Africa: Results from malaria indicator surveys," Global Health Research and Policy 3:20. doi: 10.1186/s41256-018-0075-x

Yukich, J. O., F. Tediosi, and C. Lengeler. 2007. "Operations, costs and cost-effectiveness of five insecticide- treated net programs (Eritrea, Malawi, Tanzania, Togo, Senegal) and two indoor residual spraying programs (Kwa-Zulu-Natal, Mozambique)." Basel, Switzerland: Swiss Tropical Institute.

Zamawe, C. O. F., M. Banda, and A. N. Dube. 2016. "The impact of a community-driven mass media campaign on the utilisation of maternal health care services in rural Malawi," BMC Pregnancy and Childbirth 16(21). doi: 10.1186/s12884-016-0816-0 


\section{Population Council}

4301 Connecticut Ave., NW | Suite 280

Washington, DC 20008

+12022379400

breakthroughactionandresearch.org 